\title{
Internal Feedbacks from Monsoon-Midlatitude Interactions during Droughts in the Indian Summer Monsoon
}

\author{
R. KRISHNAN AND VINAY KUMAR \\ Indian Institute of Tropical Meteorology, Pashan, Pune, India \\ M. SUGI AND J. YoshimuRA \\ Meteorological Research Institute, Tsukuba, Japan
}

(Manuscript received 26 December 2007, in final form 31 August 2008)

\begin{abstract}
Results from a 20-yr simulation of a high-resolution AGCM forced with climatological SST, along with simplified model experiments and supplementary data diagnostics, are used to investigate internal feedbacks arising from monsoon-midlatitude interactions during droughts in the Indian summer monsoon. The AGCM simulation not only shows a fairly realistic mean monsoon rainfall distribution and large-scale circulation features but also exhibits remarkable interannual variations of precipitation over the subcontinent, with the 20 -yr run showing incidence of four "monsoon droughts."

The present findings indicate that the internally forced droughts in the AGCM emanate largely from prolonged "monsoon breaks" that occur on subseasonal time scales and involve dynamical feedbacks between monsoon convection and extratropical circulation anomalies. In this feedback, the suppressed monsoon convection is shown to induce Rossby wave dispersion in the summertime subtropical westerlies and to set up an anomalous quasi-stationary circulation pattern extending across continental Eurasia in the middle and upper troposphere. This pattern is composed of a cyclonic anomaly over west central Asia and the IndoPakistan region, a meridionally deep anticyclonic anomaly over East Asia $\left(\sim 100^{\circ} \mathrm{E}\right)$, and a cyclonic anomaly over the Far East. The results suggest that the anchoring of the west central Asia cyclonic anomaly by the stagnant ridge located downstream over East Asia induces anomalous cooling in the middle and upper troposphere through cold-air advection, which reduces the meridional thermal contrast over the subcontinent. Additionally, the intrusion of the dry extratropical winds into northwest India can decrease the convective instability, so that the suppressed convection can in turn weaken the monsoon flow. The sustenance of monsoon breaks through such monsoon-midlatitude feedbacks can generate droughtlike conditions over India.
\end{abstract}

\section{Introduction}

The year-to-year variations of the Indian summer monsoon rainfall exert profound influence on agricultural production, economy, and human lives in one of the most densely inhabited regions of the world; thus, predictions of the seasonal monsoon rains have major socioeconomic implications. The physical basis for seasonal prediction in the tropics is that the low-frequency component of variability is primarily governed by slowly varying boundary forcing (e.g., SST, soil moisture, snow

Corresponding author address: R. Krishnan, Climate and Global Modelling Division, Indian Institute of Tropical Meteorology, Pashan, Pune 411008, India.

E-mail: krish@tropmet.res.in cover, etc.) so that the evolution of seasonal anomalies in the tropics is considered to be less sensitive to atmospheric initial conditions and hence more predictable as compared to the midlatitudes (Charney and Shukla 1981). This hypothesis laid the foundation for deterministic seasonal prediction in the tropics.

Although seasonal-scale variations over various tropical areas generally exhibit less dependence on the atmospheric initial state, there is also a growing recognition that the predictability of the seasonal monsoon rainfall over the Indian region, which is an exception within the tropics, tends to be limited by atmospheric internal dynamics (e.g., Palmer and Anderson 1994; Sperber and Palmer 1996; Sugi et al. 1997; Goswami 1998; Kar et al. 2001; Goswami and Xavier 2005). These studies indicate that the effect of internal dynamics on the 
Indian monsoon precipitation variability is nonnegligible and compares with the level of externally forced variability. Goswami (1998) examined simulations of the Geophysical Fluid Dynamics Laboratory (GFDL) model and estimated that internal dynamics can contribute to as much as $50 \%$ of the total variability of Indian monsoon rainfall. He noted a biennial time scale oscillation in the model simulations and suggested that such internally forced variability might arise from interactions between the subseasonal oscillations and the annual cycle.

Aspects relating to monsoon internal dynamics are not yet fully understood. On subseasonal time scales, one of the unresolved issues pertains to interactions between the monsoon circulation and extratropical flow during "monsoon breaks"-periods of well-defined large-scale interruptions in monsoon rainfall over the plains of north central India (e.g., Ramamurthy 1969; Krishnan et al. 2000; Gadgil and Joseph 2003). In an important paper, Ramaswamy (1962) pointed out that monsoon breaks were influenced by intrusion of largeamplitude westerly troughs from the midlatitudes into the Indo-Pakistan region (Indo-Pak) in the middle and upper troposphere. He noted that the intensification of the anomalous westerly troughs was accompanied by retardation in their eastward movement from west central Asia (WCA) toward the Tibetan plateau. In fact, upper-level circulation charts during weak monsoon periods indicate zonally asymmetric variations of the Tibetan high under the influence of southward penetrating midlatitude troughs (lows) over WCA and the formation of stagnant blocking highs between $90^{\circ}$ and $115^{\circ} \mathrm{E}$ over East Asia (Raman and Rao 1981).

Although the above studies are suggestive of dynamical associations between the subtropical westerlies and the upper-level tropical easterlies during the development of monsoon breaks, they also raise several scientific questions. For example, why does the amplitude of the westerly troughs over Indo-Pak increase during monsoon breaks? What is the underlying dynamics behind the stagnation of the westerly troughs over the Indo-Pak region (Ramaswamy 1962) and the blocking ridge over East Asia (Raman and Rao 1981) during prolonged break spells? In an earlier study, Krishnan et al. (2000) had pointed out that the large-scale suppression of convection during the evolution of monsoon breaks forces a Rossby wave response to the west of the subcontinent. A question arises as to whether these Rossby waves might interact with the subtropical westerly flow. Ding and Wang (2007) have recently reported significant teleconnection between the summer circulation across Eurasia and the Indian monsoon convection on subseasonal time scales. Because the summertime upper-tropospheric westerlies over the Eurasian region act as a waveguide and allow generation of stationary patterns (see Ambrizzi et al. 1995; Terao 1999; Enomoto et al. 2003; Ding and Wang 2005), this issue relating to prolonged monsoon breaks and droughts provides a germane ground for gaining deeper insight about the dynamical feedbacks between the monsoon and midlatitude circulation.

In this paper we have examined simulations from a 20-yr integration of a high-resolution AGCM forced with seasonally varying climatological global SST to advance our understanding of the internal dynamics of monsoon-midlatitude interactions associated with monsoon breaks and drought conditions over the subcontinent. Additionally, we have conducted sensitivity experiments using a simplified atmospheric model, together with diagnostic analyses of various data products to supplement the AGCM simulations. The details of the AGCM and datasets are described in the next section.

\section{AGCM and datasets}

\section{a. $A G C M$}

The AGCM used here is a version of the Japan Meteorological Agency (JMA) global spectral model. It has a T106 horizontal resolution (triangular truncation at zonal wavenumber 106), with 21 vertical levels based on a hybrid coordinate system (JMA 1993; Kar et al. 1996). The parameterization of various physical processes in the AGCM is described in Sugi et al. (1990). We have conducted a $20-y r$ integration of the above AGCM by prescribing a seasonally varying climatological SST as a lower boundary condition. The SST boundary condition does not vary interannually; rather, it repeats every year during the 20-yr run. The SST data is from the Atmospheric Model Intercomparison Project II (AMIP II; http://www-pcmdi. llnl.gov/projects/amip/). Besides the 20-yr AGCM run, the monsoon-midlatitude teleconnection dynamics is examined through supplementary experiments with a forced divergent barotropic vorticity model (see section 6). The advantage of this model is its simplicity; it facilitates deeper understanding of the dynamical link between break-monsoon convection and the midlatitude circulation anomalies, which is not readily discernible from the AGCM simulation alone.

\section{b. Datasets used}

This study also includes diagnostic analyses of datasets from multiple sources for interpreting the AGCM simulations. The atmospheric parameters are from the 
National Centers for Environmental Prediction (NCEP) reanalysis (Kalnay et al. 1996); the gridded land/ocean rainfall is from the Climate Prediction Center (CPC) Merged Analysis of Precipitation (CMAP) dataset (http://www.cpc.noaa.gov/products/global_precip/html/ wpage.cmap.html), which is a product of merging rain gauge observations and precipitation estimates from satellites; and the observed outgoing longwave radiation (OLR) comes from NOAA satellite data (http://www.cdc.noaa. gov/cdc/data.interp_OLR.html). The above datasets used in our analysis cover the period 1979-2004.

\section{Analyses of mean monsoon simulation}

The mean features of the South Asian summer monsoon, based on the AGCM simulation, NCEP reanalysis, and CMAP datasets, are presented below. The mean climatology in the AGCM is based on the average of the 20-yr run.

\section{a. Seasonal rainfall and low-level winds}

Figure 1a shows the June-September (JJAS) seasonal mean monsoon rainfall and winds at $850 \mathrm{hPa}$ simulated by the AGCM. The corresponding fields from the CMAP and NCEP reanalysis are shown in Fig. 1b. It can be noticed that the simulation captures the southwest monsoon low-level cross-equatorial winds over the Indian Ocean and the westerly flow over the subcontinent and the adjoining Arabian Sea and Bay of Bengal. The overall distribution of monsoon rainfall over the Indian region is quite robust in the simulation. The simulated rainfall clearly shows the precipitation maxima along the west coast and the head Bay of Bengal, although it may be noted that the model produces excessive precipitation near the Western Ghat Mountains and the Himalayan foothills as compared to the CMAP rainfall. Also seen in the simulation is the secondary rainfall maximum between $5^{\circ}-10^{\circ} \mathrm{S}$ over the Indian longitudes. Closer comparison of Figs. 1a and $1 \mathrm{~b}$ suggests that the model underestimates the rainfall over the near-equatorial region $\left(0-5^{\circ} \mathrm{N}\right)$, the South China Sea and the Philippines, and the adjoining tropical west Pacific. The model bias over the South China Sea and tropical west Pacific is consistently reflected in the weaker low-level winds in Fig. 1a as compared to Fig. 1b. In noting these biases, it must be mentioned that an accurate representation of the Asian summer monsoon rainfall has remained a major challenge for most state-of-the-art GCMs (e.g., Gadgil and Sajani 1998; Kang et al. 2002; Wang et al. 2004). Moreover, the model discrepancies in terms of the finer details should not affect the overall impetus of our study, especially given the large-scale nature of the monsoon circulation.

\section{b. Upper and middle tropospheric circulation features}

A characteristic feature of the boreal summer monsoon is the formation of the Tibetan anticyclone in the upper troposphere (Krishnamurti 1973) and the Tropical Easterly Jet (TEJ) which has its core axis located near $150 \mathrm{hPa}$ around the $15^{\circ} \mathrm{N}$ latitude (Koteswaram 1958). Numerous studies have shown that the Tibetan Plateau acts as an elevated heat source that maintains the upper-tropospheric anticyclone during the boreal summer (e.g., Flohn 1957; Koteswaram 1958; Krishnamurti 1973; Hahn and Manabe 1975; Luo and Yanai 1984; Yanai and Wu 2006; Liu et al. 2007). Here, we examine the mean upper-tropospheric circulation at $200 \mathrm{hPa}^{1}$ from the AGCM simulation (Fig. 2a) and the NCEP reanalysis (Fig. 2b). It can be noticed that the upper-level easterlies in the AGCM are located mostly southward of $20^{\circ} \mathrm{N}$, with a longitudinal extent covering the Asian and African monsoon regions. The simulated maximum wind speeds, exceeding $23 \mathrm{~m} \mathrm{~s}^{-1}$, are stronger than those in the NCEP reanalysis. The Tibetan anticyclone, with its ridge axis around $25^{\circ} \mathrm{N}$, is also prominently depicted in the simulation. Furthermore, the upper-level circulation (Figs. 2a,b) shows strong westerlies located poleward of $30^{\circ} \mathrm{N}$ beyond the northern flank of the Tibetan anticyclone, with the westerly winds being stronger in the AGCM than in the NCEP reanalysis. The westerly jet core near $40^{\circ} \mathrm{N}$, with wind speeds $>30 \mathrm{~m} \mathrm{~s}^{-1}$, is known in the terminology as the Asian Jet (Enomoto et al. 2003).

Figure $2 \mathrm{c}$ shows the mean circulation and temperature at $500 \mathrm{hPa}$ simulated by the AGCM; the corresponding fields from the NCEP reanalysis are shown in Fig. 2d. The midtroposphere over the monsoon region approximately corresponds to the level of maximum vertical velocity, which implies nondivergence (Rodwell and Hoskins 1996). Note that the 500-hPa winds over the Indian region are not as strong as the low-level monsoon flow. A striking feature in the midtroposphere is the anticyclonic circulation over Arabia, Iran, northern Africa, and the eastern Mediterranean (Figs. 2c,d). This feature is associated with summertime descent over the subtropical desert regions (see Rodwell and Hoskins 1996), with the midtropospheric subtropical westerlies being located poleward of $30^{\circ} \mathrm{N}$.

\footnotetext{
${ }^{1}$ Here $200 \mathrm{hPa}$ is chosen as the reference level for the upper tropospheric circulation because both the monthly and daily outputs from the AGCM simulation are available at this level. Furthermore, the circulation at $200 \mathrm{hPa}$ also provides information about the TEJ and the Tibetan anticyclone.
} 

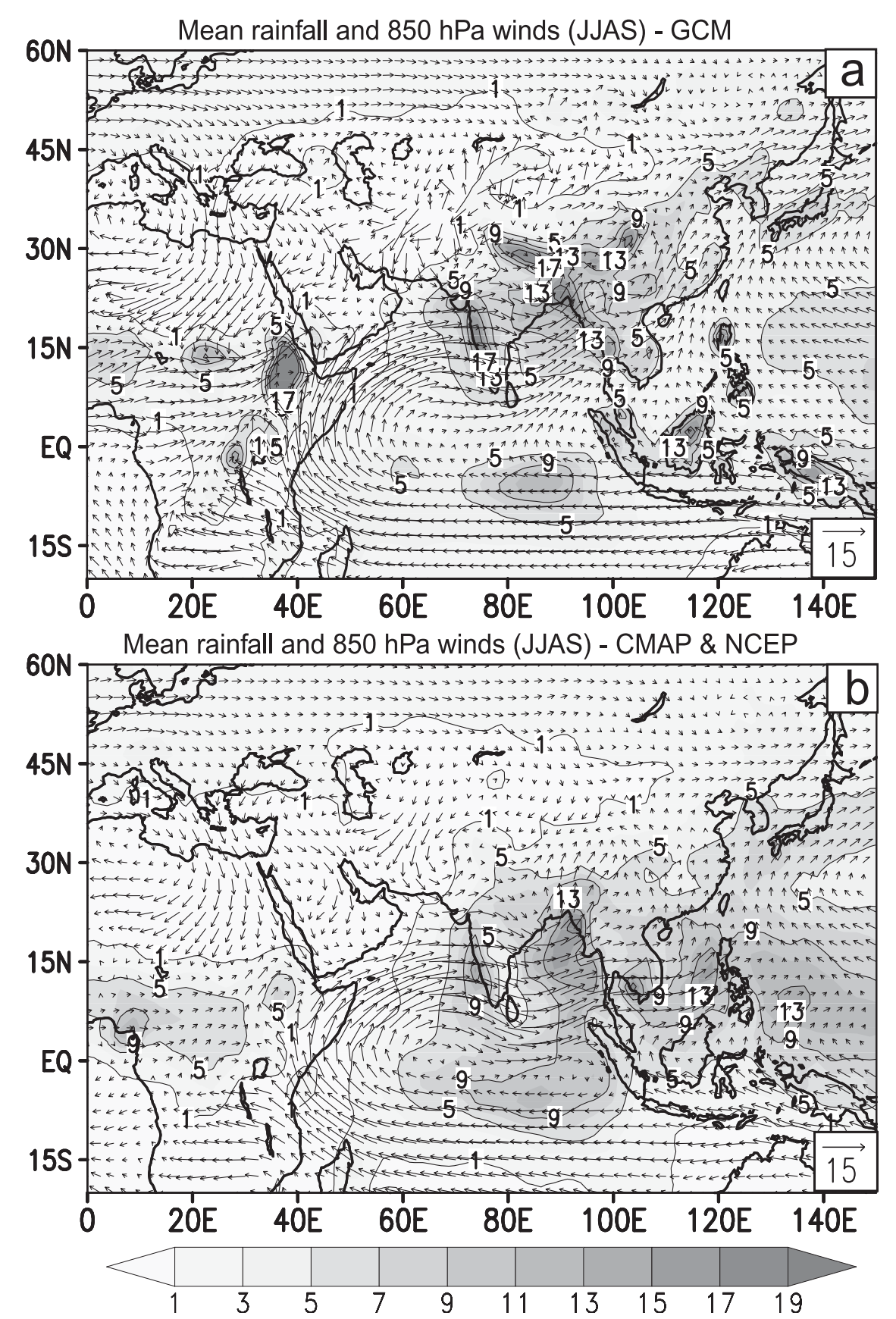

FIG. 1. Mean rainfall $\left(\mathrm{mm} \mathrm{day}^{-1}\right)$ and $850-\mathrm{hPa}$ winds $\left(\mathrm{m} \mathrm{s}^{-1}\right)$ for the JJAS monsoon season: (a) GCM, (b) CMAP (rainfall) and NCEP reanalysis winds. The mean fields in the GCM are computed from the 20-yr simulation. For the CMAP/NCEP data, the climatology is based on the period 1979-2004.

Additionally, we draw attention to the midtropospheric temperature field (Figs. 2c,d) - an effective indicator of the large-scale thermal response to monsoonal heating. Basically, the elevated boreal summer heating over the Tibetan Plateau acts as a thermal forcing that warms the troposphere and sets up a large-scale meridional tem- perature gradient over the Indian longitudes (Yanai and Wu 2006). It is seen from Figs. 2c,d that the maximum midtropospheric temperature exceeds $270 \mathrm{~K}$ and occurs over the Indo-Tibet region and China; vast areas covering the South and East Asian monsoon regions have temperatures exceeding $268 \mathrm{~K}$. Notice that the mean 

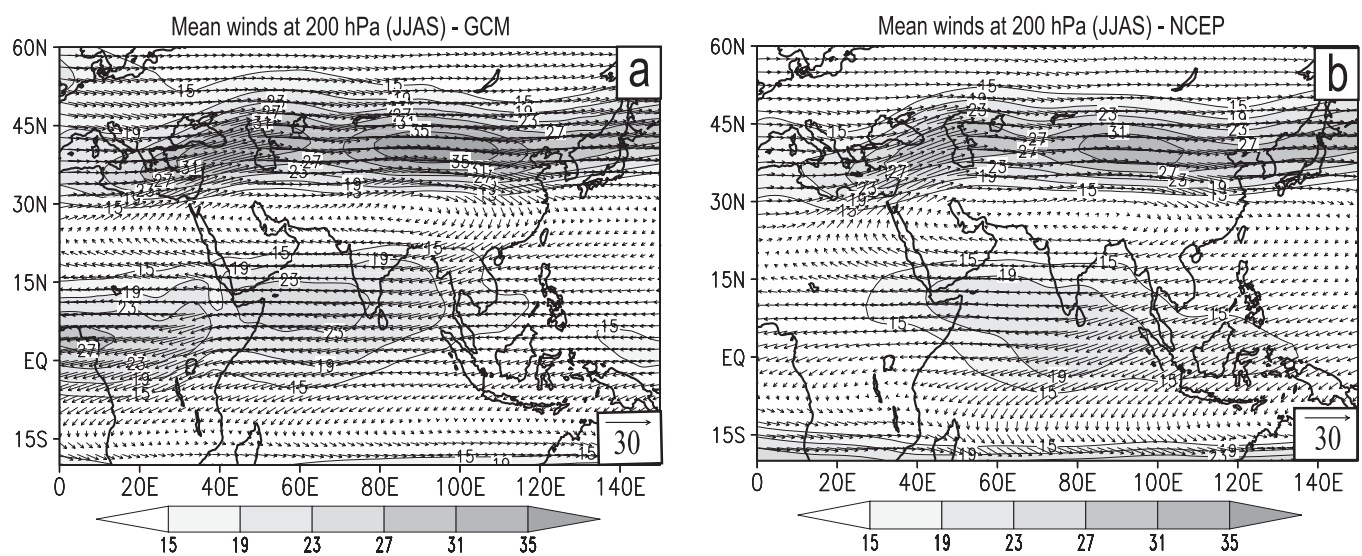

Mean winds \& temperature at $500 \mathrm{hPa}$ (JJAS) - GCM
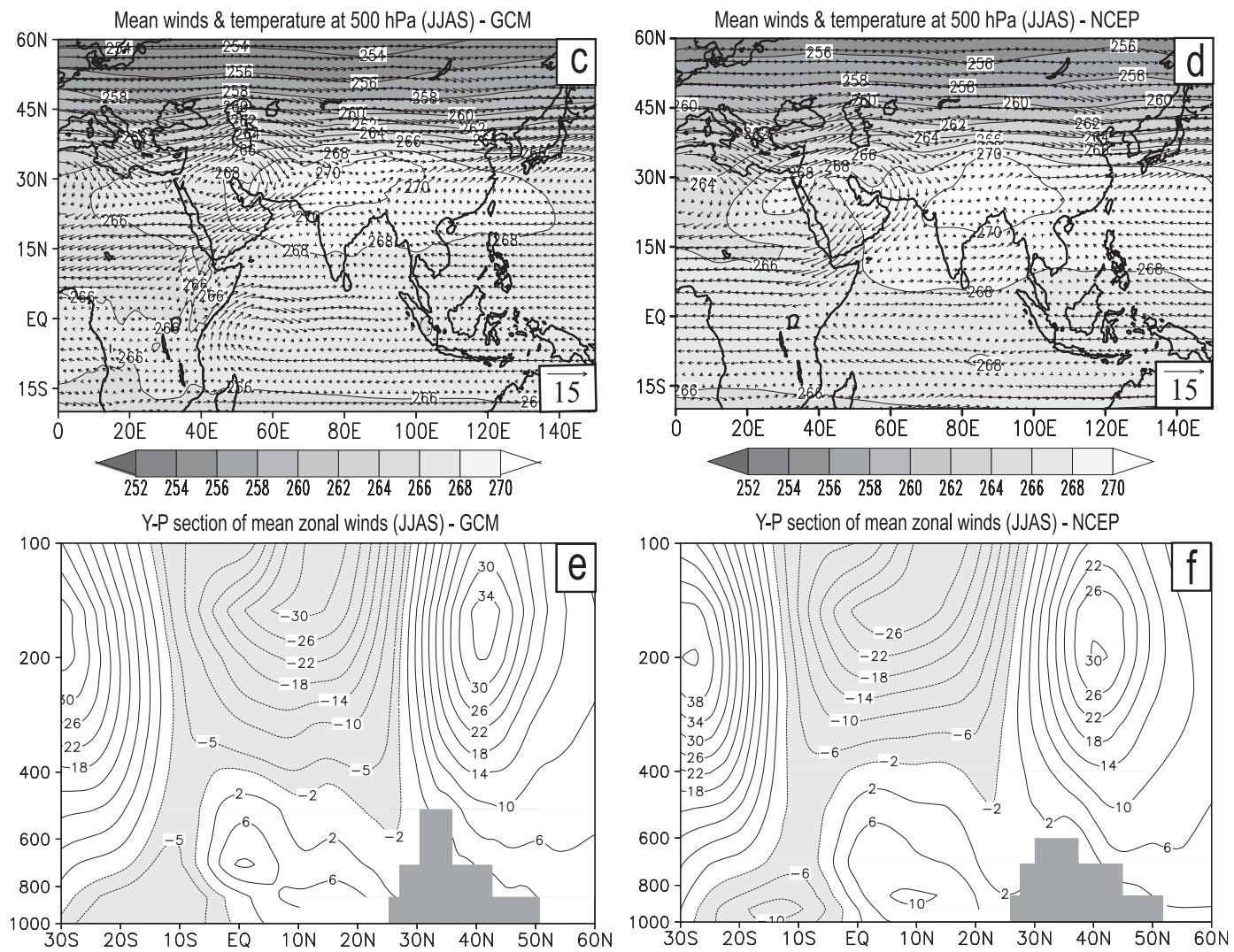

FIG. 2. Mean circulation for the JJAS monsoon season in the (left) GCM and (right) NCEP reanalysis. (a),(b) Wind speed (shading) and winds $\left(\mathrm{m} \mathrm{s}^{-1}\right)$ at $200 \mathrm{hPa}$. (c),(d) Winds $\left(\mathrm{m} \mathrm{s}^{-1}\right)$ and temperature (K) at $500 \mathrm{hPa}$. (e),(f) Latitude-pressure sections of zonal winds $\left(\mathrm{m} \mathrm{s}^{-1}\right)$ averaged over the Indian longitudes $\left(75^{\circ}-85^{\circ} \mathrm{E}\right)$.

temperatures decrease rapidly poleward of $35^{\circ} \mathrm{N}$, whereas the variation is more gradual between the Tibetan region and the tropical Indian Ocean. The simulated 500-hPa temperature shows some differences as compared to NCEP reanalysis; for example, the region of maximum temperature is shifted more westward in the model, and the simulated temperatures over the west Pacific are not as warm as compared to NCEP reanalysis. In noting these differences, it should be mentioned that the primary purpose of comparing the model simulation with NCEP reanalysis is not to focus critically on the accuracy of simulation; instead, the idea is to ensure that the large-scale monsoonal characteristics are represented with a fair degree of realism in the simulation. In fact, it may be noted from Figs. 2c,d that the temperature difference between $30^{\circ} \mathrm{N}$ and $15^{\circ} \mathrm{S}$, over the Indian longitudes $\left(\sim 80^{\circ} \mathrm{E}\right)$, is about $4 \mathrm{~K}-$ suggesting the robustness of the simulated large-scale meridional temperature 
gradient between the subcontinent and tropical Indian Ocean.

A consolidated picture of the vertical structure of zonal winds across different latitude belts is provided by the latitude-pressure section averaged over the Indian longitudes $\left(75^{\circ}-85^{\circ} \mathrm{E}\right)$, both for the simulation (Fig. 2e) and the NCEP reanalysis (Fig. 2f). The monsoon lowlevel cross-equatorial flow, with easterlies to the south and westerlies to the north of the equator, is evident in the simulation. Above $400 \mathrm{hPa}$, the zonal winds between $10^{\circ} \mathrm{S}$ and $20^{\circ} \mathrm{N}$ are characterized by strong easterlies and the TEJ is seen around $150 \mathrm{hPa}$ where the maximum zonal wind speed is about $30 \mathrm{~m} \mathrm{~s}^{-1}$. Also note that the zonal winds in the $15^{\circ} \mathrm{S}-25^{\circ} \mathrm{N}$ tropical belt exhibit a strong vertical shear between the lower and upper troposphere. On the other hand, the midlatitude westerlies in both hemispheres can be seen extending throughout the depth of the troposphere, with the NH westerlies being pushed more poleward compared to those in the $\mathrm{SH}$. In the $\mathrm{NH}$, the core of westerly maximum is located beyond $40^{\circ} \mathrm{N}$ and is near the $200-\mathrm{hPa}$ level, whereas the westerly core in the $\mathrm{SH}$ is located around $30^{\circ} \mathrm{S}$. Comparison of Figs. 2e and 2f shows that the upper-level tropical easterlies are stronger in the model as compared to the NCEP reanalysis. Also, the midlatitude westerlies associated with the Asian Jet are stronger in the AGCM relative to the NCEP reanalysis. Despite these differences, there is good resemblance in the overall large-scale structure of the zonal wind distribution between the simulation (Fig. 2e) and the NCEP reanalysis (Fig. 2f).

\section{Interannual variability of the monsoon simulation}

\section{a. Interannual variability of summer monsoon rainfall}

We shall now examine the interannual variability of the summer monsoon rainfall from the 20-yr AGCM simulation. Figure 3 a shows the standard deviation (std dev) of the monsoon rainfall from the AGCM; the corresponding std dev map for CMAP rainfall (1979-2004) is shown in Fig. 3b. It can be seen that the std dev values are higher than $2 \mathrm{~mm}$ day $^{-1}$ over the west coast of India, the head of the Bay of Bengal, and the southern equatorial Indian Ocean in Figs. 3a,b. The std dev values over the Indian landmass are generally higher in the AGCM as compared to the CMAP values. Also, it can be noticed that the precipitation variability in the AGCM is quite high over the Himalayan foothills and the Indo-China region. The important point to our discussion is the strong interannual variability of the Indian monsoon rainfall exhibited by the 20 -yr run with a climatological
SST boundary condition. This is consistent with the results of Kar et al. (2001), who examined two long runs of the JMA model using first a climatological SST boundary condition and then an interannually varying SST boundary forcing and noted that the std dev of the Indian monsoon rainfall was comparable in the two runs.

Figure $3 \mathrm{c}$ shows the time series of interannual variability of monsoon rainfall over the Indian region (12$32^{\circ} \mathrm{N}, 70-90^{\circ} \mathrm{E}$ ) from the $20-\mathrm{yr}$ AGCM run; the corresponding CMAP time series is shown in Fig. 3d (lightshaded bars) for the period 1979-2004, along with the all-India summer monsoon rainfall (AISMR) anomalies shown by the dark-shaded histogram in Fig. 3d. The mean and std dev of the rainfall indices are indicated in Figs. 3 c,d. Note that the 20 -yr period of the simulation is arbitrary, and the simulated interannual variability is unrelated to the observed variability during (1979-2004). Our intention is not to make a one-to-one comparison of the simulated and observed variability; instead, the objective is to show that the levels of interannual variability of monsoon rainfall in the two cases are comparable. It is interesting to note that the 20 -yr simulation shows four cases of droughts with rainfall deficiencies exceeding $10 \%$ of the mean; two of them exhibit deficiencies above $20 \%$. It is also seen that the time series (Fig. 3c) gives the impression of a decadal-like variability, the cause of which is not clear. Understanding this issue is beyond the scope of the present paper and will require a separate study. Nevertheless, the important point here is the occurrence of significant monsoon internal variability, which is evident in other models as well (e.g., Goswami 1998). For instance, we have further noted significant interannual variations in the Indian monsoon rainfall in a 35-yr long simulation of the Portable Unified Model (PUM) of the UK Met Office (http://ugamp.nerc.ac.uk/ $\mathrm{um} /$ ) based on a climatological SST boundary condition repeated year after year (not shown).

\section{b. Anomaly composites during monsoon droughts}

We now examine composites of rainfall and low-level circulation anomalies based on the four monsoon droughts in the simulation (Fig. 4a). These drought cases correspond to the years $(7,8,10$, and 11) from the 20-yr run for which the seasonal monsoon rainfall departures are below $-10 \%$ of the normal. Similar anomaly composites are constructed using the NCEP reanalysis and CMAP data for the seven monsoon droughts (i.e., 1979, 1982, 1985, 1986, 1987, 2002, and 2004) that occurred during 1974-2004 (shown in Fig. 4b). Note that the seven observed monsoon droughts, as classified by the India Meteorological Department, are defined when the AISMR during a given year is deficient by more than $10 \%$ of the climatological normal (http://www.tropmet.res.in). 
Rainfall (JJAS) standard deviation: GCM
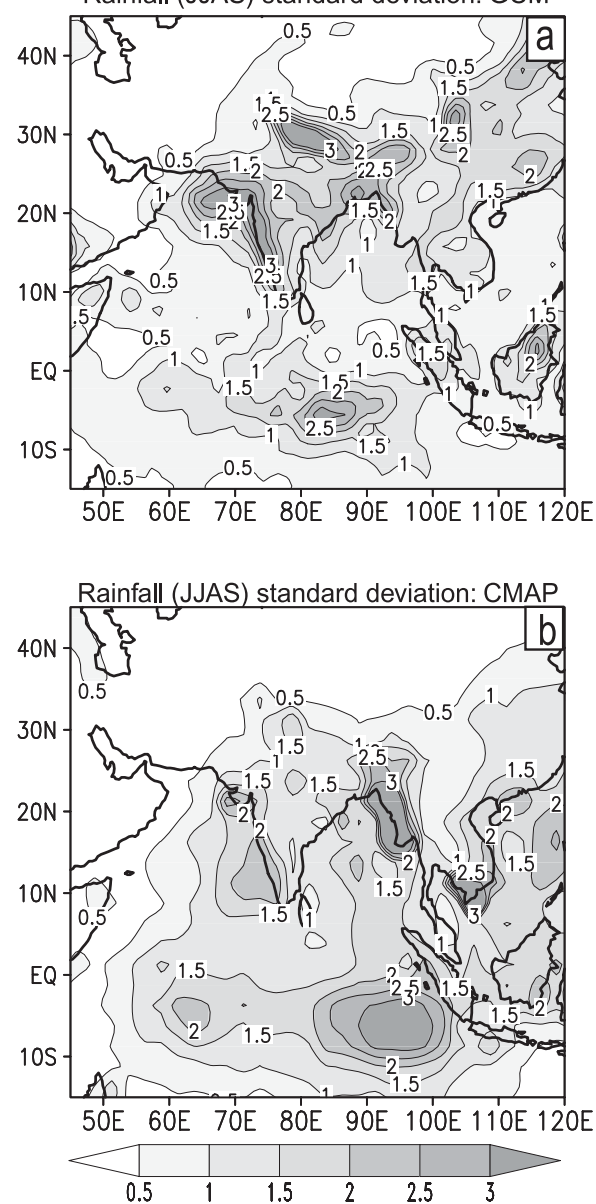

Interannual variations of the Indian summer monsoon rainfall
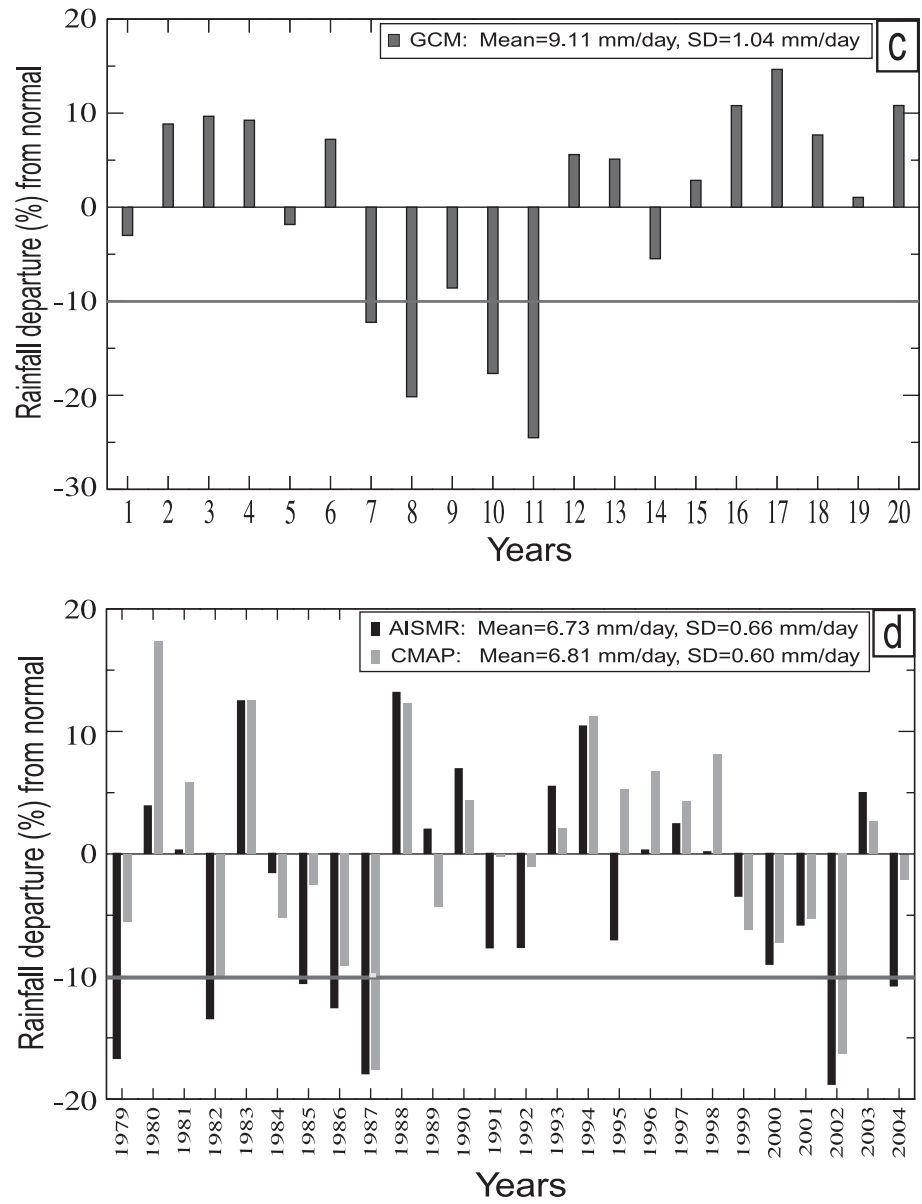

FIG. 3. (left) Std dev maps of the JJAS summer monsoon rainfall (mm day ${ }^{-1}$ ) for (a) GCM and (b) CMAP. (right) Time series of the interannual variability of summer monsoon rainfall over the Indian region $\left(12^{\circ}-32^{\circ} \mathrm{N}, 70^{\circ}-90^{\circ} \mathrm{E}\right)$ for (c) $\mathrm{GCM}$ and (d) CMAP and AISMR data. The rainfall variations in (c) and (d) are expressed as the percentage departure from normal, and the $-10 \%$ rainfall departure is shown by a solid horizontal line. The AISMR index in (d) is based on rainfall from a fixed set of 306 uniformly distributed rain gauge stations over India (Parthasarathy et al. 1995).

As mentioned earlier, the observed anomaly map (Fig. 4b) is used only to ensure consistency of the model simulation in terms of the large-scale anomalous features observed during drought periods. The anomaly composites show a weakened summer monsoon, as evidenced from the rainfall reduction and the anomalous low-level anticyclone over the subcontinent and the Arabian Sea in Figs. 4a,b. It may be noted that the magnitude of precipitation and wind anomalies over the Indian landmass is larger in the simulation (Fig. 4a) as compared to the CMAP-NCEP reanalysis (Fig. 4b). A noteworthy aspect of the model simulation is the anomalous low-level westerlies over the south equatorial Indian Ocean $\left(5^{\circ} \mathrm{S}-0^{\circ}\right.$, $60^{\circ}-100^{\circ} \mathrm{E}$ ), which is characteristic of weak monsoon conditions (see Rodwell 1997; Krishnan et al. 2006). The simulation also reveals an east-west band of enhanced precipitation extending from the Burma-Thailand region into eastern China and the northwest Pacific. The anomalous precipitation enhancement over eastern China and the Far East (Fig. 4a) is a feature typically observed during monsoon breaks (Krishnan et al. 2000). This point will be taken up for discussion subsequently.

\section{c. Upper and middle tropospheric circulation anomalies}

Anomaly composites of 200-hPa winds during monsoon drought periods are shown for the model (Fig. 5a) and for NCEP reanalysis (Fig. 5b). Note that the circulation anomalies (Figs. 5a,b) are dominated by anomalous westerlies over the subcontinent, which essentially correspond to weakening of the upper-tropospheric easterly flow. A remarkable feature in Figs. 5a,b is the anomalous cyclonic circulation over the midlatitude region 

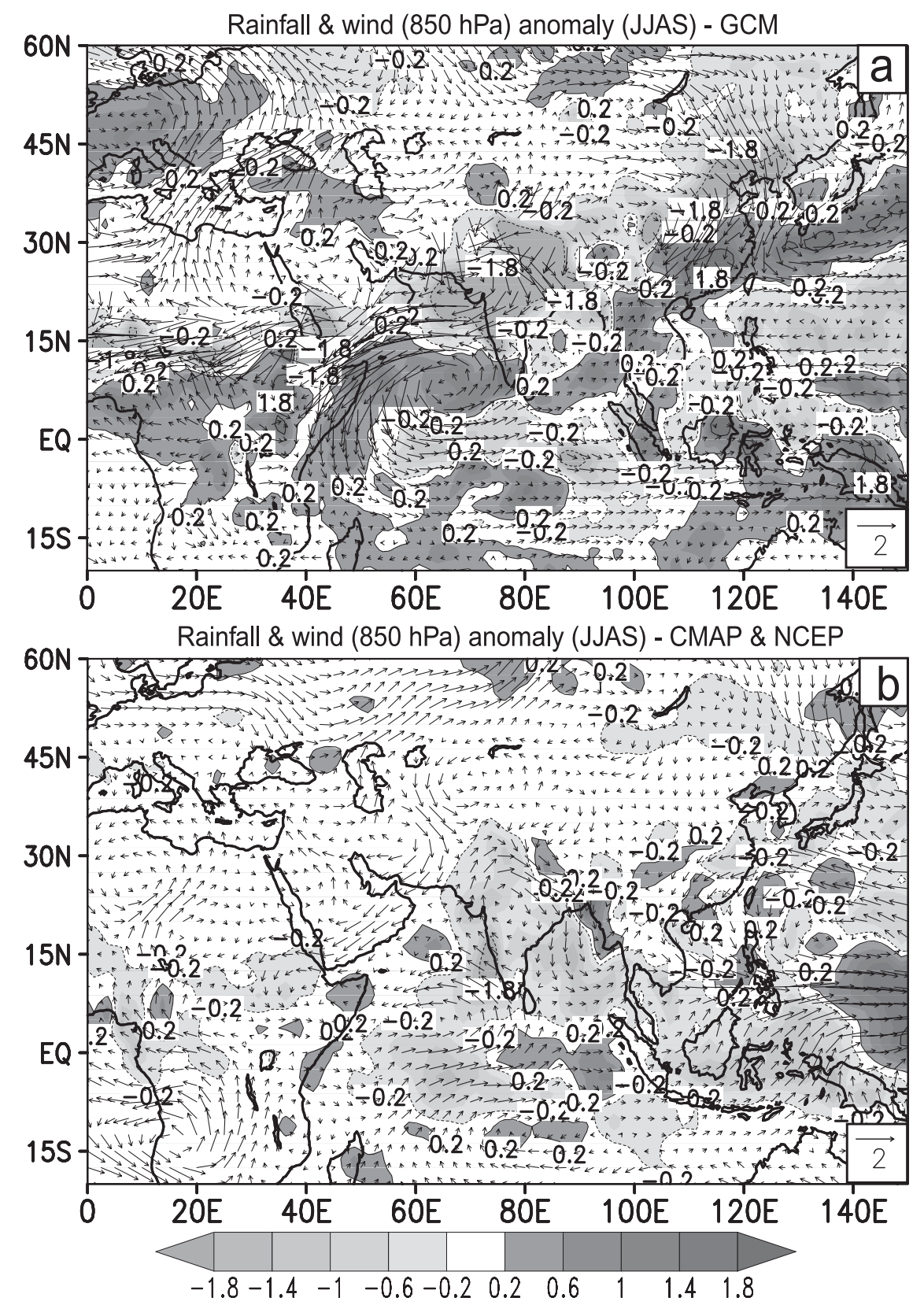

FIG. 4. Anomaly composites of the seasonal (JJAS) monsoon rainfall (mm day ${ }^{-1}$ ) and 850 hPa winds $\left(\mathrm{m} \mathrm{s}^{-1}\right.$ ) based on drought years: (a) GCM; (b) CMAP/NCEP dataset. The monsoon droughts in the GCM correspond to the years 7, 8, 10, and 11 of the 20 -yr model run. The CMAP-NCEP composites are based on the seven observed monsoon droughts during 1979, 1982, 1985, 1986, 1987, 2002, and 2004 when the seasonal monsoon rainfall anomalies had departures below $-10 \%$ of the normal.

located to the east of the Caspian Sea. This cyclonic anomaly, embedded in the westerly winds, has a fairly extended horizontal scale stretching from the Mediterranean region up to about $85^{\circ} \mathrm{E}$. It is important to note that the anomalous westerlies over WCA extend considerably southward and intrude into the Indo-Pak region and north central India. Furthermore, the midlatitude cyclonic anomaly has an equivalent barotropic structure and can be seen over much of the tropospheric depth. In fact, the cyclonic anomaly can be clearly noticed at $500 \mathrm{hPa}$ (Figs. 5c,d), which shows the penetration of the westerly anomalies into the Indian region. 

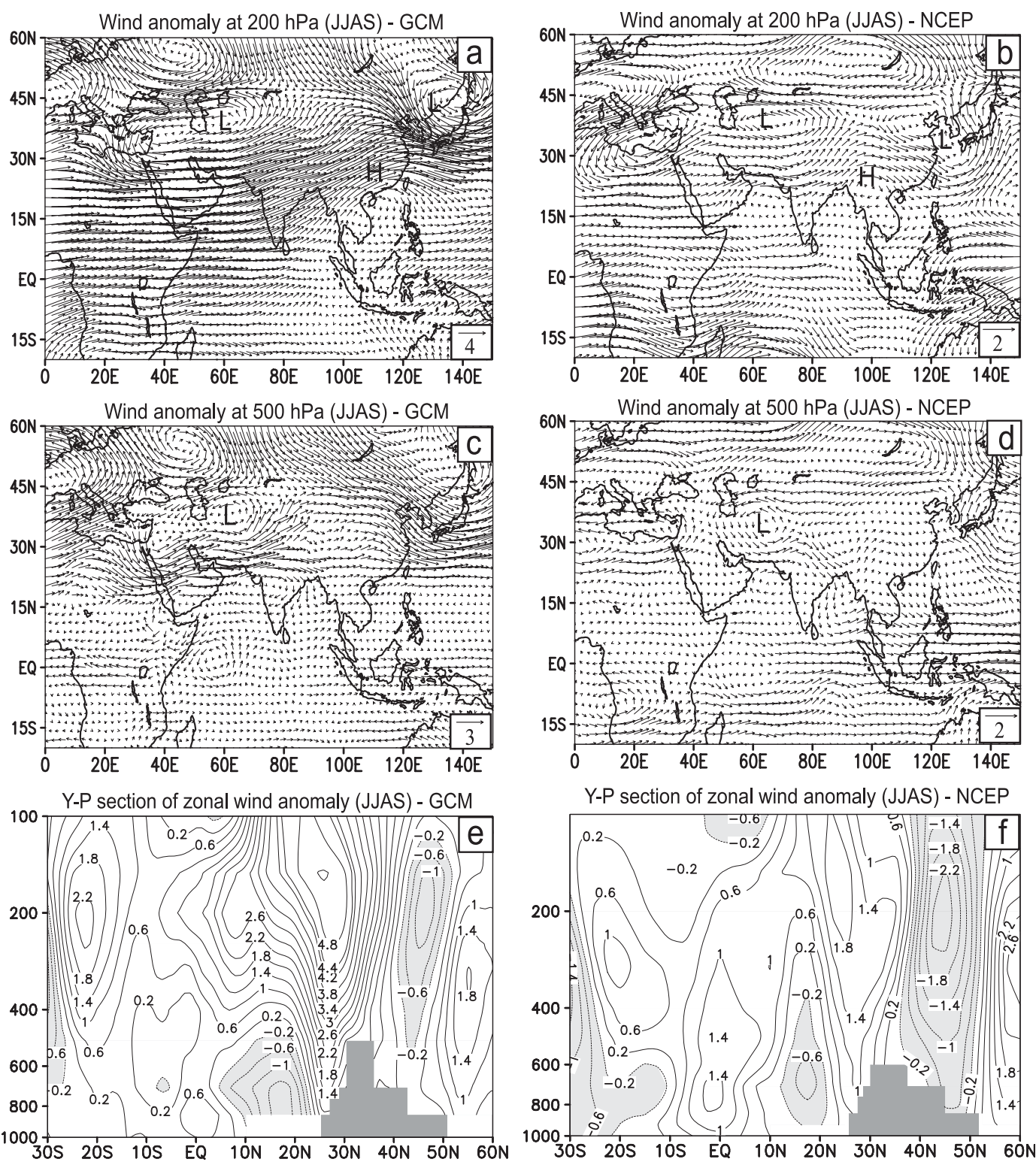

FIG. 5. Composites of the seasonal (JJAS) anomalies based on monsoon droughts in the (left) GCM and (right) NCEP reanalysis. (a)-(d) Wind $\left(\mathrm{m} \mathrm{s}^{-1}\right)$ anomalies at (a),(b) 200 and (c),(d) $500 \mathrm{hPa}$. (e),(f) Latitude-pressure sections of zonal wind anomalies $\left(\mathrm{m} \mathrm{s}^{-1}\right)$ averaged over the Indian longitudes $\left(75^{\circ}-85^{\circ} \mathrm{E}\right)$.

Several studies have alluded to the above anomalous features in the upper and middle troposphere during weak episodes of the Indian monsoon (e.g., Ramaswamy 1962; Keshavamurty and Awade 1974; Kripalani et al. 1997; Krishnan et al. 1998; Joseph and Srinivasan 1999; Krishnan and Sugi 2001). Further, it may be noticed that the pervasiveness of the uppertropospheric westerly anomalies in Figs. 5a,b is not just restricted to the $\mathrm{NH}$ but also dominates over the $\mathrm{SH}$. In fact, Ramaswamy and Pareek (1978) pointed out that the atmospheric general circulation in both the hemi- spheres tends to be locked in a low-index Rossby regime during intensely weak phases of the monsoon.

The upper-level circulation anomalies reveal a ridge over East Asia around the $100^{\circ} \mathrm{E}$ longitude in the NCEP reanalysis (Fig. 5b), which is shifted further eastward in the AGCM toward eastern China (Fig. 5a). Raman and Rao (1981) suggested the possible role of the stagnant East Asia ridge in anchoring of the cyclonic anomaly over WCA and the Indo-Pak region during weak monsoons. This anomalous ridgelike feature is known to be associated with an eastward 
shift of the upper-tropospheric anticyclone and increased rainfall activity over Indo-China (Krishnamurti et al. 1989). In fact, the simulation shows anomalous precipitation enhancement over the Burma-Thailand region and eastern China (Fig. 4a). Notice that the East Asia ridge extends meridionally from the tropics $\left(\sim 18^{\circ} \mathrm{N}\right)$ into the midlatitudes $\left(\sim 45^{\circ} \mathrm{N}\right)$. In particular, a well-defined anticyclonic anomaly can be seen near $50^{\circ} \mathrm{N}, 100^{\circ} \mathrm{E}$ in the NCEP reanalysis (Fig. 5b); it resembles a midlatitude blocking (Raman and Rao 1981). Further eastward, a cyclonic anomaly is seen (Figs. 5a,b) over eastern China, Korea, and Japan. This east-west pattern of cyclonic anomaly over WCA, a ridge over East Asia, and a cyclonic anomaly further eastward is reminiscent of the teleconnection that links the out-of-phase rainfall variability over the Baiu and the Indian monsoon region during early summer (Krishnan and Sugi 2001). A similar midlatitude circulation pattern extending across the Eurasian region was proposed by Enomoto et al. (2003) to explain the formation of the Bonin High during August.

Latitude-pressure sections of zonal wind anomaly composites (Figs. 5e,f) show a prevalence of westerly anomalies in the middle and upper troposphere over the monsoon region. In fact, the westerly anomalies are evident over the tropics in both hemispheres. The amplitude of the westerly anomalies is much stronger in the model simulation as compared to the NCEP reanalysis. The anomalous easterlies to the north of $40^{\circ} \mathrm{N}$ correspond to a weakened Asian Jet (Fig. 5f). The weakening of the Asian Jet is not as pronounced in the simulation, which appears to be related to the occurrence of strong westerly anomalies extending far to the north of $35^{\circ} \mathrm{N}$ over northern China and Mongolia in the simulation (see Fig. 5a). The anomalous easterlies between $10^{\circ}$ and $20^{\circ} \mathrm{N}$ in the lower troposphere (Figs. 5e,f) indicate a weakened southwest monsoon circulation.

\section{d. Tropospheric temperature anomalies}

Composites of the temperature anomalies at 200 and $500 \mathrm{hPa}$, based on monsoon drought years, are shown for the AGCM (Figs. 6a,c) and NCEP reanalysis (Fig. $6 \mathrm{~b}, \mathrm{~d})$. Cold temperature anomalies can be prominently seen over the Indian subcontinent and WCA and further westward over the Mediterranean region. The cold anomalies over the Indo-Pak and WCA are associated with the southward-intruding anomalous troughs in the midlatitude westerlies. The magnitude of the cold anomalies is much larger in the AGCM as compared to the NCEP reanalysis. For example, the maximum cooling over WCA at $500 \mathrm{hPa}$ is about $-2.2^{\circ} \mathrm{C}$ in the simulation, as compared to the cooling of about $-0.6^{\circ} \mathrm{C}$ in the
NCEP reanalysis. Basically, the anomalous tropospheric cooling over WCA and the subcontinent (Figs. 6a-d) decreases the north-south temperature gradient over the Indian longitudes (Keshavamurty and Awade 1974; Krishnan et al. 1998; Li and Yanai 1996). The NCEP reanalysis maps show small positive temperature anomalies over East Asia (Figs. 6b-d), which appear to be related to the anomalous ridge over the region. This feature is masked in the simulation because of the dominance of cooling associated with the strong westerly wind anomalies. We have examined anomaly composites of horizontal temperature advection $[-(\mathbf{V} \cdot \nabla T)]$ at 500 $\mathrm{hPa}$ (Figs. 6e,f). It can be clearly seen that the horizontal advection anomalies show a strong cooling tendency over the Indo-Pak region, which has magnitude of about $-1.0^{\circ} \mathrm{C} \mathrm{day}^{-1}$ in the model simulation and nearly $-0.3^{\circ} \mathrm{C}$ day $^{-1}$ in the NCEP reanalysis.

It is important to note that the cold anomaly over WCA and the Indo-Pak and Eurasian regions covers a large area; the cooling also extends through much of the middle and upper troposphere. Figure 7 shows the vertically integrated (600-200 $\mathrm{hPa}$ ) temperature and wind anomaly during drought periods. The maximum cooling is $\sim-1.3^{\circ} \mathrm{C}$ in the AGCM (Fig. 7a) and about $-0.52^{\circ} \mathrm{C}$ in the NCEP reanalysis (Fig. $7 b$ ). The westerly anomalies over the Indo-Pak region have a magnitude of about $4 \mathrm{~m} \mathrm{~s}^{-1}$ in the AGCM, whereas the corresponding magnitude in the NCEP reanalysis is about $2 \mathrm{~m} \mathrm{~s}^{-1}$. Because the southward-intruding midlatitude westerly anomalies are associated with dry winds, they can affect the convective instability. The convective instability in the tropics can be inferred from the vertical structure of moist static energy (MSE), which typically decreases with height in the lower and middle troposphere and again increases with height in the upper troposphere (Asnani 1993, 529-537). Using the vertical profiles of temperature and humidity from the GCM, we examined the vertical profile of MSE over the region $60^{\circ}-80^{\circ} \mathrm{E}, 15^{\circ}-30^{\circ} \mathrm{N}$, covering northwest India and environs under climatological mean conditions and during drought periods (figures not shown). Over this region, the intraseasonal convection anomalies are known to be related to the Eurasian midlatitude wave train (Ding and Wang 2007). The MSE values were found to be lower during drought periods as compared to the mean climatology. Furthermore, the negative gradient of MSE was weaker during drought periods, indicating a weaker convective instability. The value of CAPE computed for the climatological mean condition was $\sim 1910$ $\mathrm{J} \mathrm{kg}^{-1}$, whereas the value during drought periods was $\sim 540 \mathrm{~J} \mathrm{~kg}^{-1}$. Here, it is worth mentioning that the Tropical Ocean and Global Atmosphere Coupled Ocean-Atmosphere Response Experiment (TOGA 

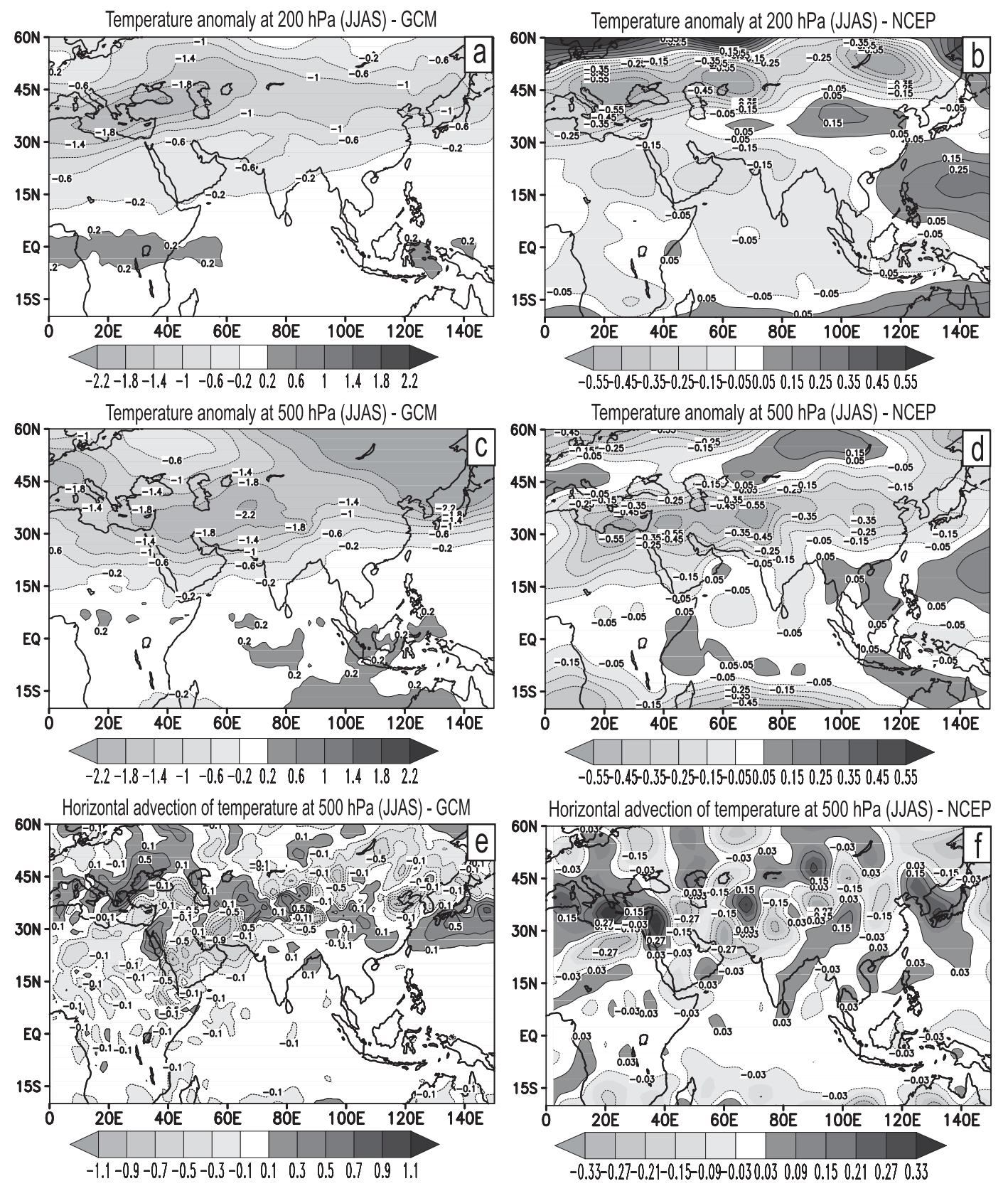

FIG. 6. As in Fig. 5, but for temperature (K) anomalies. (a)-(d) Temperature anomalies at (a),(b) 200 and (c),(d) 500 $\mathrm{hPa}(\mathrm{K})$. (e),(f) Anomalies of horizontal advection of temperature at $500 \mathrm{hPa}\left(\mathrm{K}_{\text {day }}{ }^{-1}\right)$.

COARE) observations showed that episodes of anomalous drying in the midtroposphere can discourage the growth of deep convective clouds due to depletion of parcel buoyancy (Brown and Zhang 1997). Based on the above points, it is suggested that the intrusion of midlatitude anomalies into northwest India and neighborhood can inhibit convective instability; suppressed convection may in turn weaken the monsoon flow (Krishnan et al. 2000).

\section{Monsoon breaks in the AGCM simulation}

\section{a. Identification of monsoon break days}

Studies have reported that the internal dynamics over the Indian monsoon region may arise from the subseasonal or intraseasonal time scale variability associated with the active/break monsoon spells (see Goswami and Xavier 2005). Because the structure of the intraseasonal anomalies has significant impact on the spatial structure of the 

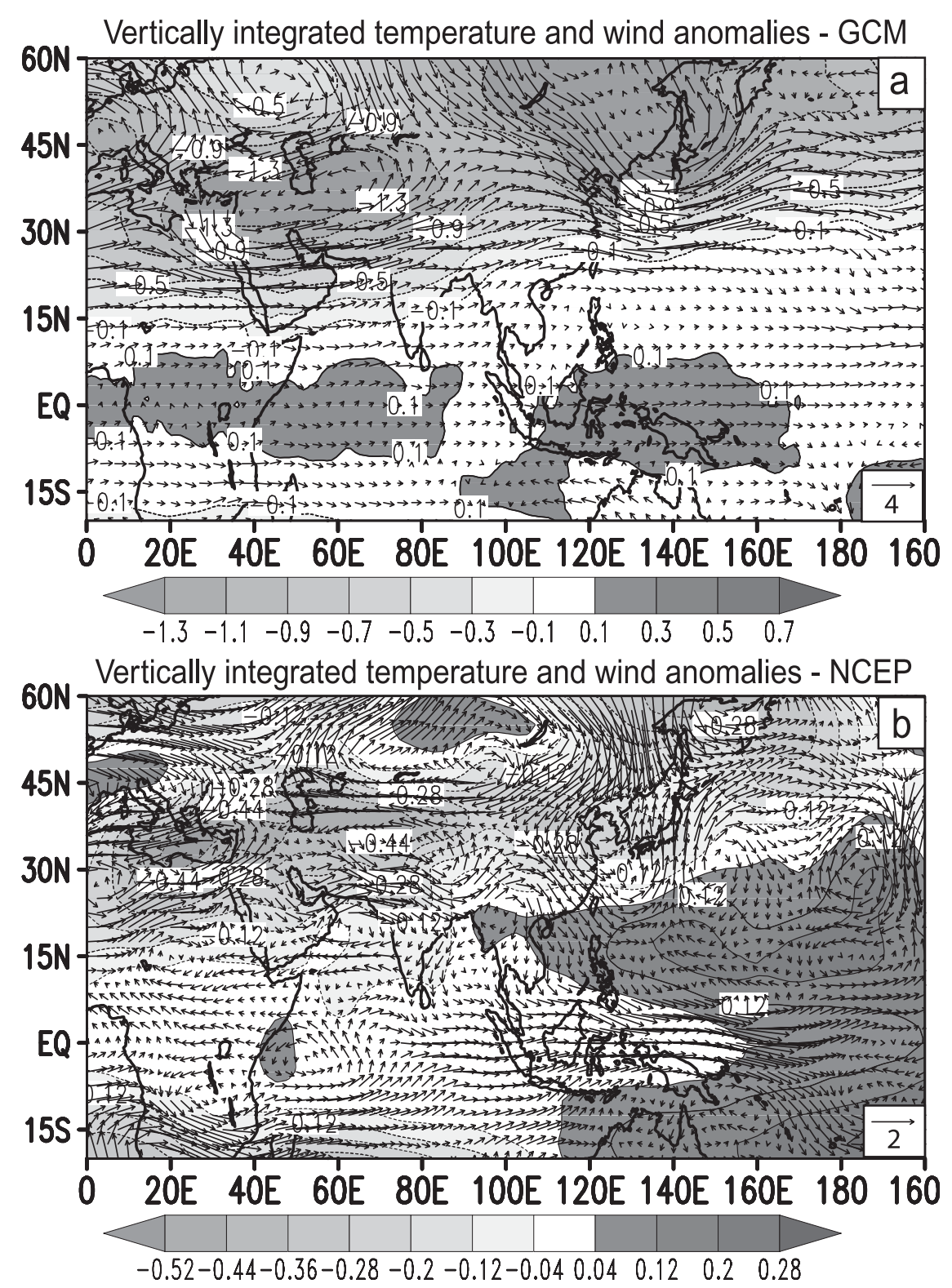

FIG. 7. Composite maps of vertically integrated temperature $(\mathrm{K})$ and wind $\left(\mathrm{m} \mathrm{s}^{-1}\right)$ anomalies during monsoon droughts: (a) GCM; (b) NCEP reanalysis. The anomalies for the JJAS season are integrated vertically over the middle and upper troposphere $(600-200 \mathrm{hPa})$.

seasonal anomalies (Ferranti et al. 1997; Sperber et al. 2000; Goswami and Ajaya Mohan 2001), it implies that the occurrence of active/break phases of the monsoon intraseasonal variability can significantly determine the seasonal monsoon anomaly for a given year. To understand whether the model-simulated droughts were dominated by an incidence of monsoon break spells, we have examined daily outputs of rainfall and circulation from the AGCM simulation. Figure 8 shows daily rainfall anomalies from June through September, averaged over a wide area of the Indian region, for each of the four drought years. The daily anomalies were computed relative to daily means prepared from daily outputs of the 20-yr run. The criterion devised for selecting the break days is that the percentage departure of the area-averaged rainfall from normal should be less than $-20 \%$ for at least four consecutive days. In adopting the above definition, we keep in mind the broad pattern of observed rainfall departures during breaks (Ramamurthy 1969); this criterion for identifying monsoon breaks in model simulations is similar to that used by Krishnan et al. (2003). Moreover, the condition that each break spell should last for at least 

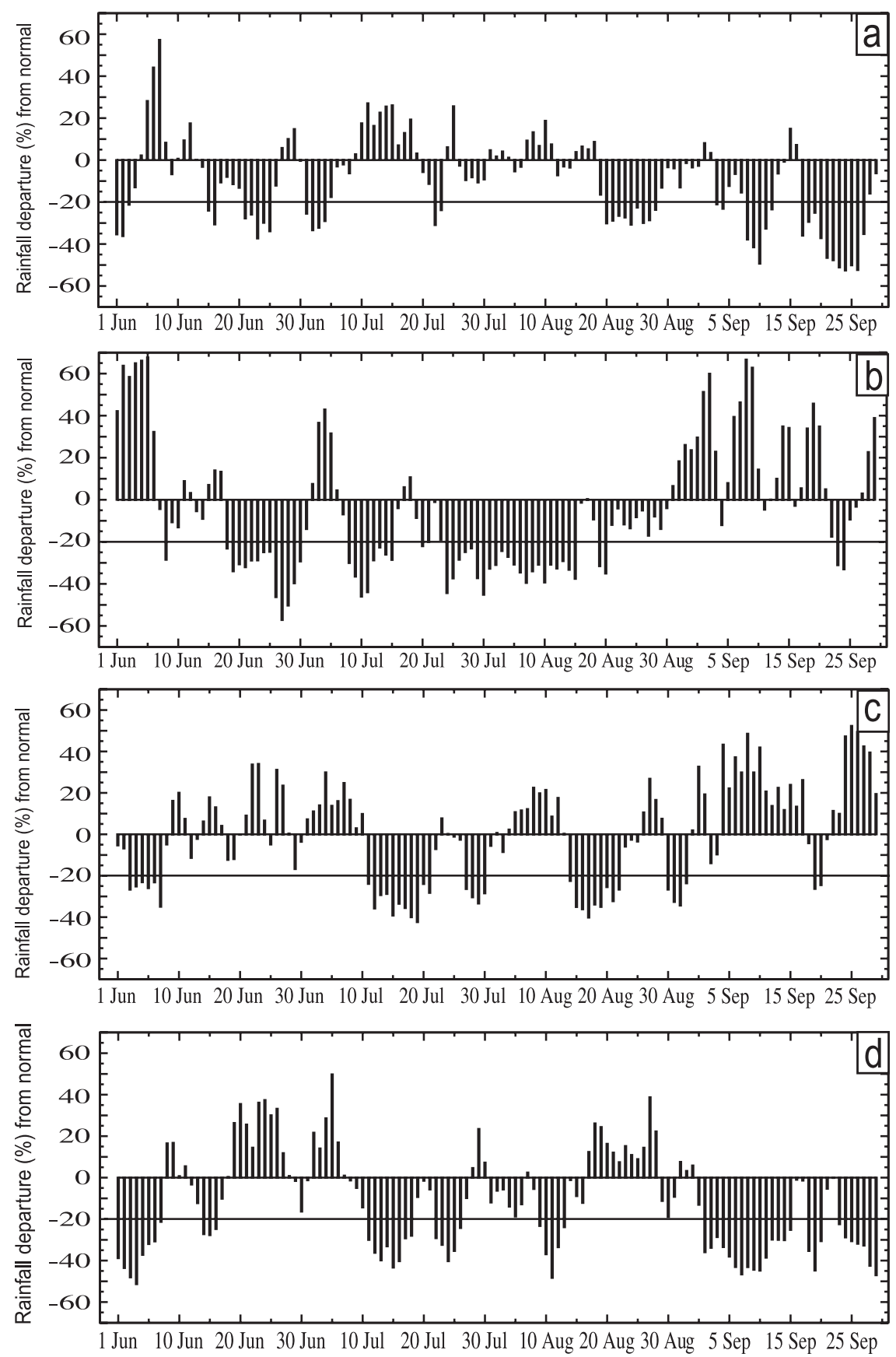

FIG. 8. Daily rainfall anomalies from 1 Jun to 30 Sep averaged over a wide area of the Indian subcontinent $\left(12^{\circ}-32^{\circ} \mathrm{N}, 70^{\circ}-90^{\circ} \mathrm{E}\right)$ for the four monsoon droughts from the 20-yr GCM run: (a) 7 th, (b) 8 th, (c) 10 th, and (d) 11th year. The daily anomalies were computed relative to daily normals prepared from daily rainfall output of the 20 -yr model run. The criteria for selecting the monsoon break days is that the percentage departure of the area-averaged rainfall from the normal should be less than $-20 \%$ (shown by a solid horizontal line) for at least four consecutive days. The number of break days in the four drought years was found to be $34,43,34$, and 48 days, respectively. 
four consecutive days ensures that the identified periods of rainfall deficiency are not too short.

Using the above criterion, the number of break days during the monsoon season for the four drought years were found to be $34,43,34$, and 48 days respectively. From Fig. 8, it is seen that the simulated droughts are typically associated with four to six break spells within the monsoon season; however, some of the longest breaks have a duration of $11-15$ days. The frequency distribution of the daily rainfall anomalies for the four drought cases (Fig. 9a) shows peaks corresponding to negative rainfall departures. In other words, the skewed structure of the distributions more toward negative departures indicates that break spells dominated the monsoon intraseasonal variability during the four drought years in the simulation. We have further examined the statistics of breaks during the five strong monsoon cases (years 3, 4, 16, 17, and 20) from the 20-yr AGCM run. The number of break days during the above five strong monsoons were noted to be $11,4,6,11$, and 5 days, respectively (not shown). Figure $9 \mathrm{~b}$ shows a comparison of the frequency distribution of daily rainfall anomalies between strong and weak monsoons. It can be noticed that the distribution for the weak monsoon (strong monsoon) is skewed more to the negative (positive) rainfall departures, indicating that breaks tend be more frequent and predominant during drought periods relative to strong monsoons.

\section{b. Anomaly composites during monsoon breaks}

Composite maps of rainfall and circulation anomalies based on the break days during the four drought years in the simulation are shown in Fig. 10. Additionally, we have prepared anomaly composites from the NCEP reanalysis corresponding to the observed break days during the period 1979-2004. The observed break days, which have been adopted from Krishnan et al. (2000), are determined using National Oceanic and Atmospheric Administration (NOAA) OLR data-a good proxy for tropical convection. For consistency purposes, the break days during 1979-2004 (Table 1) are selected only for the years that were associated with monsoon droughts (i.e., 1979, 1982, 1985, 1986, 1987, 2002, and 2004). Our intention in showing the break anomalies both for the AGCM and the NCEP reanalysis is to basically ensure a fair degree of realism and consistency in the simulation of the large-scale structure of the monsoon break anomaly patterns.

Figures 10a,b show break composites of rainfall and 850-hPa wind anomalies from the simulation and the NCEP reanalysis. The suppressed rainfall and low-level anticyclonic anomaly over the subcontinent are clearly evident in the simulation. The increased precipitation/ convective activity over the south equatorial Indian Ocean, northeast India, Indo-China, the northwest $\mathrm{Pa}$ cific, and the Far East in Figs. 10a,b is a characteristic feature of monsoon breaks (e.g., Lau and Chan 1986; Krishnan et al. 2000, 2006; Sperber et al. 2000; Annamalai and Sperber 2005). The anomaly composites of 200-hPa winds (Figs. 10c,d) show a cyclonic anomaly near the Caspian Sea and WCA and anomalous westerlies over Indo-Pak and northern India. Further ahead, an upperlevel anticyclonic anomaly can be seen over the area around $100^{\circ} \mathrm{E}$ in the $\mathrm{NCEP}$ reanalysis (this is shifted eastward to $\sim 110^{\circ} \mathrm{E}$ in the AGCM). This feature is associated with an intensified upper-level anticyclonic circulation due to increased rainfall activity over the region (see Krishnamurti et al. 1989). It is also important to note that the northern flank of the anticyclonic anomaly extends meridionally into the midlatitudes in the form of a blocking ridge up to about $45^{\circ} \mathrm{N}$, as reported earlier by Raman and Rao (1981). Farther northeastward, a cyclonic anomaly can be seen near Korea and Japan. The pattern of anomalous highs $(\mathrm{H})$ and lows (L) in Figs. 10c,d resembles a wave train extending from the deep midlatitudes into the subtropics and tropical monsoon regions.

Examination of the break composites of temperature anomalies at $500 \mathrm{hPa}$ reveals anomalous cooling of about $-1^{\circ} \mathrm{C}$ over WCA, Indo-Pak, northern India, and the Tibet-China region (Figs. 10e,f). Note that the cold anomalies extend farther northeastward into the Korean Peninsula and the Far East, whereas warm anomalies are seen around $15-30^{\circ} \mathrm{N}$ over China and East Asia. Warm anomalies are also seen over northwest Eurasia to the north of the Caspian and Black Seas. Basically, the warm anomalies correspond to regions of anticyclonic anomaly, while the cold anomalies are associated with cold-air advection by the midlatitude troughs embedded in the westerlies. Note that the warm anomalies over the tropical Indian Ocean in the NCEP reanalysis (Fig. 10f) are nearly absent in the simulation (Fig. 10e). It is not obvious whether the weak temperature response over the tropical Indian Ocean in the AGCM is related to the absence of interannually varying SST boundary forcing in the 20-yr run. However, this should not really impact the thrust of our analysis. The important point emerging from this discussion is the broad resemblance between the monsoon break pattern of large-scale circulation anomalies and the anomaly pattern during monsoon droughts. This implies that the spatial structure of the monsoon break anomalies tends to be projected on the structure of the seasonal anomalies during monsoon droughts, thus indicating the importance of subseasonal variability in giving rise to internally forced droughts in the AGCM. 

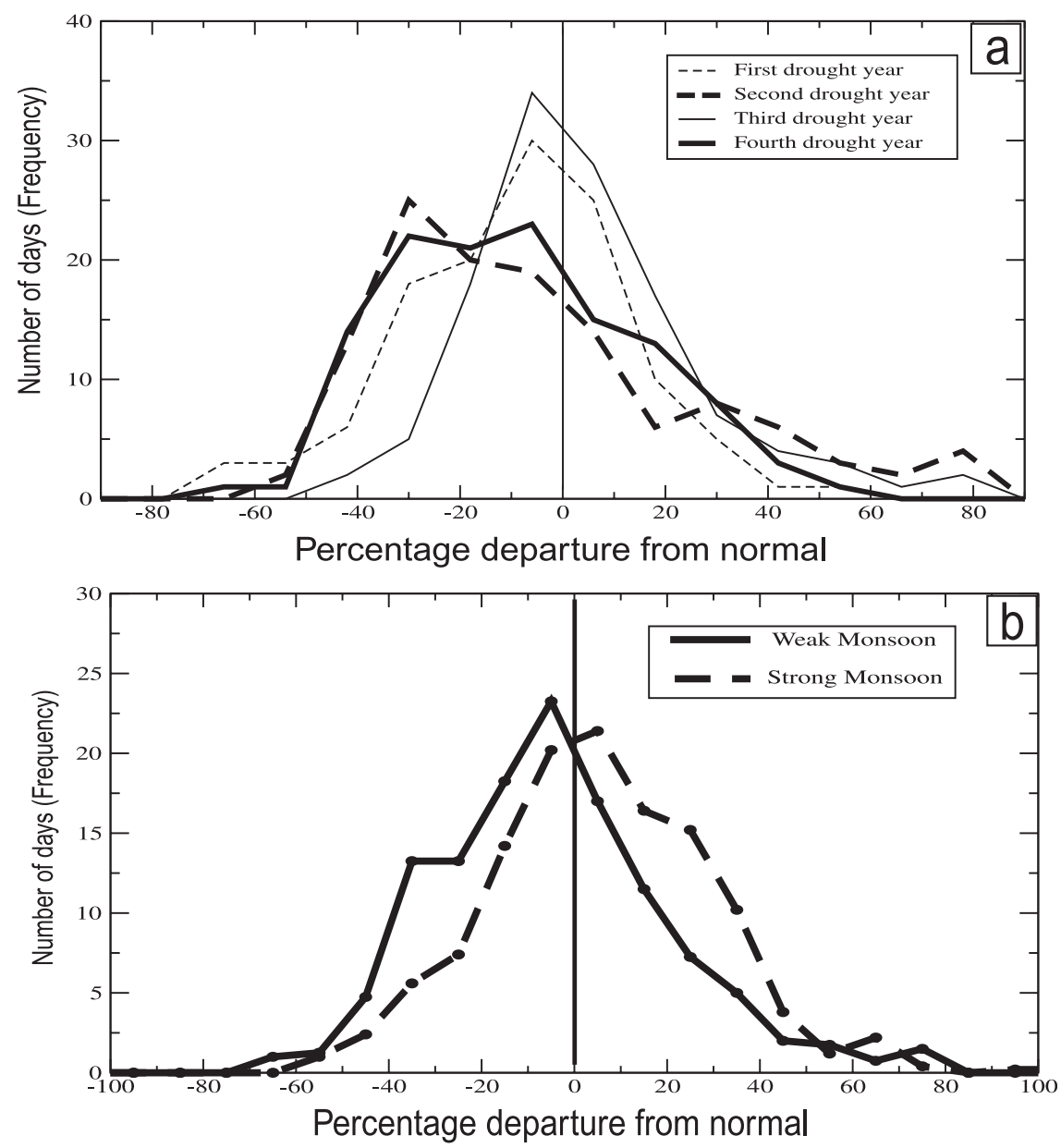

FIG. 9. (a) Frequency distribution of daily rainfall departures for 122 days (1 Jun-30 Sep) for the four monsoon droughts from the 20 -yr run. The rainfall anomalies are averaged over the region $12^{\circ}-32^{\circ} \mathrm{N}, 70^{\circ}-90^{\circ} \mathrm{E}$. (b) Comparison of the mean frequency distributions of rainfall departures between weak (solid line) and strong (dashed line) monsoon years. Weak monsoons are based on the years $(7,8,10$, and 11$)$ having rainfall deficiencies exceeding $-10 \%$ of normal. Strong monsoons are based on the years $(3,4,16,17$, and 20$)$ with rainfall anomaly exceeding $+10 \%$ of normal. The mean frequency distribution is obtained by averaging the individual distributions for the two cases separately.

\section{c. Evolution of the midlatitude circulation anomalies}

Ramaswamy (1962) reported retardation in the eastward movement of the midlatitude troughs that intensified in amplitude and protruded into the Indo-Pak region during monsoon breaks. Raman and Rao (1981) attributed this feature to the formation of stagnant upper tropospheric blocking ridges over East Asia at $\sim 100^{\circ} \mathrm{E}$, which extend deep into the midlatitudes. Here we examine the propagation of upper-level circulation anomalies associated with monsoon breaks in the model simulation (Figs. 11a-d) and NCEP reanalysis (Figs. $11 \mathrm{e}-\mathrm{h})$, based on the time sequence of 3-day averaged (triad) anomaly composites. In general, triad $n$ refers to the composite averaged over days $3 n-1,3 n$, and $3 n+1$. Thus, triad 0 , which corresponds to commencement of a monsoon break spell, refers to the average over days $-1,0$, and +1 . The triads preceding a break spell are triads $-1,-2, \ldots$ and those following a break spell are triads $+1,+2, \ldots$.

The simulation shows an anomalous low over the Eastern Mediterranean in triad -2. At this stage the upper-level westerly anomalies are not prominent over the Indian region (Fig. 11a). The low intensifies and quickly moves eastward from triads -2 to -1 so that it lies to the east of the Caspian Sea (Fig. 11b). At this stage, westerly anomalies prevail over northern parts of the subcontinent, whereas an anomalous high is seen 

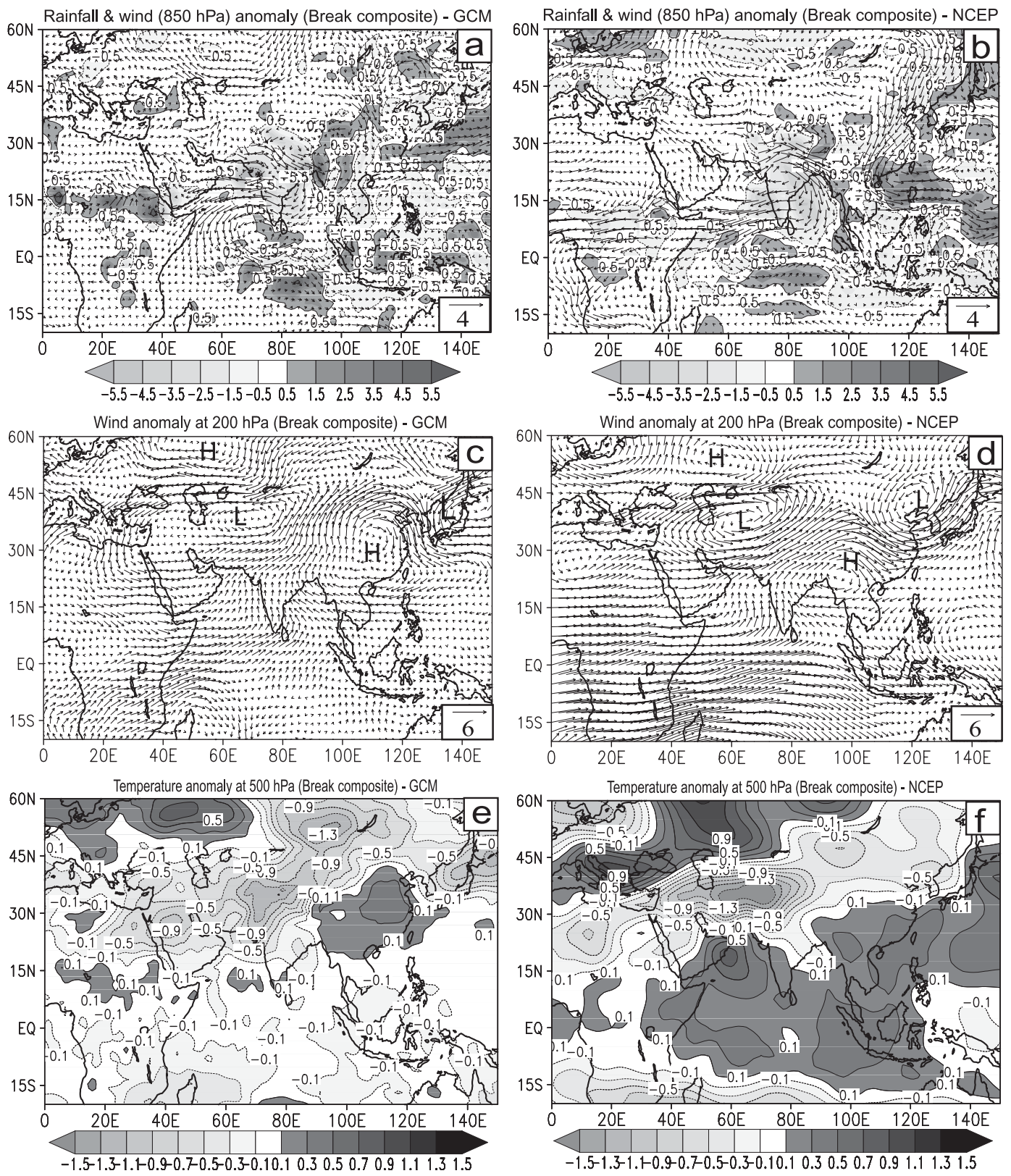

FIG. 10. Anomaly composites based on monsoon break days in the (left) GCM and (right) NCEP reanalysis. (a),(b) Rainfall (mm day ${ }^{-1}$ ) and 850-hPa-wind ( $\mathrm{m} \mathrm{s}^{-1}$ ) anomalies. (c),(d) The 200-hPa wind $\left(\mathrm{m} \mathrm{s}^{-1}\right)$ anomalies. (e),(f) The 500-hPa temperature $(\mathrm{K})$ anomalies. In preparing the anomaly composites, the monsoon break days are considered only during drought years (see Fig. 4). Table 1 gives a list of break days during the seven observed monsoon drought years $(1979,1982,1985,1986,1987,2002$, and 2004).

over East Asia and the Taiwan region. Notice that the high over East Asia intensifies and extends westward in triads 0 and +1 ; the ridgelike feature extends meridionally up to nearly $50^{\circ} \mathrm{N}$ (Figs. $11 \mathrm{c}, \mathrm{d}$ ). The cyclonic anomaly over WCA shows a slight southeastward movement from triads -1 to 0 , but most importantly the low is anchored over Indo-Pak vicinity and intensifies in amplitude in triads 0 and +1 . Note that the amplified trough over Indo-Pak is accompanied by an almost stagnant anticyclonic anomaly farther ahead of the trough line (Figs. 11c,d). Although there are some differences in the amplitudes of the AGCM and NCEP anomalies, the overall evolutionary characteristics of the cyclonic anomaly over WCA and the downstream anticyclonic anomaly are broadly similar in Figs. 11a-d and Figs. 11e-h. 
TABLE 1. List of break days for the seven monsoon droughts during 1979-2004.

\begin{tabular}{cclc}
\hline \hline Case & Year & \multicolumn{1}{c}{ Break period } & Number of days \\
\hline 1 & 1979 & 01 July-06 July & 06 \\
2 & & 18 July-22 July & 05 \\
3 & & 12 August-27 August & 16 \\
4 & & 02 September-07 September & 06 \\
5 & 1982 & 24 June-07 July & 14 \\
6 & 1985 & 29 June-03 July & 05 \\
7 & & 23 August-26 August & 04 \\
8 & & 05 September-08 September & 04 \\
9 & 1986 & 20 August-08 September & 20 \\
10 & 1987 & 14 July-03 August & 21 \\
11 & & 30 August-02 September & 04 \\
12 & 2002 & 05 July-16 July & 12 \\
13 & & 20 July-30 July & 11 \\
14 & 2004 & 21 June-02 July & 12 \\
15 & & 10 July-15 July & 06 \\
16 & & 19 July-23 July & 05 \\
17 & & 24 August-03 September & 11 \\
& & & Total $=162$ \\
\hline
\end{tabular}

Maps of rainfall anomalies corresponding to triads $-2,-1,0$, and +1 are shown in Figs. $12 \mathrm{a}-\mathrm{d}$. The rainfall anomalies in triads -2 and -1 show decreased rainfall mostly over northwest India, whereas positive anomalies can be seen over peninsular and northeastern India in Figs. 12a,b. A widespread rainfall deficit covering the whole of the Indian subcontinent is seen in triads 0 and +1 . Figures $12 \mathrm{e}$, f show lagged regression maps between the upper-level circulation and Indian monsoon rainfall anomalies. Note that the cyclonic anomaly over WCA and the anticyclonic anomaly over the East Asian region $\left(\sim 105^{\circ} \mathrm{E}\right)$ are prominent in triads $-1,0$, and +1 , which is indicative of the teleconnection between the rainfall anomalies and the midlatitude wave train. In triad -2 , the cyclonic anomaly over WCA is somewhat weak in magnitude and the East Asian anticyclonic anomaly is not very prominent. Basically, as the monsoon rainfall deficiency becomes prominent in triads -1 , 0 , and +1 , one can notice a strengthening of the WCA cyclonic anomaly and the East Asian anticyclone. The anticyclonic anomaly further northwest of WCA (near $60^{\circ} \mathrm{E}, 55^{\circ} \mathrm{N}$ ) appears to be part of the midlatitude wave train. Although the dynamics of this anomalous high is not fully clear, it is conceivable that the circulation response over WCA, associated with monsoon convection changes, can be communicated farther north through the midlatitude wave train (Hoskins and Karoly 1981).

\section{Extratropical response during monsoon breaks}

Anomalous tropical convection can induce vorticity changes over the subtropics and midlatitudes through interactions between the divergence anomalies and the subtropical westerlies (Hoskins and Karoly 1981; Sardeshmukh and Hoskins 1988; Lau and Peng 1992; Krishnan and Mujumdar 1999). The question addressed here pertains to the dynamical link between the anomalous midlatitude circulation pattern and the suppressed convection over the Indian subcontinent during monsoon breaks; it is important for gaining insight into the dynamical maintenance of the anomalous low over WCA and the Indo-Pak region and the stagnant ridge over East Asia. Krishnan et al. (2000) pointed out that suppressed convection anomalies over the Indian region, during the evolution of monsoon breaks, forced off-equatorial Rossby waves that propagated to the west. The issue here is to clarify the possible interactions between the Rossby waves and the subtropical westerlies penetrating into the subcontinent during monsoon breaks and to provide a dynamical explanation for the midlatitude circulation pattern over Eurasia. We have conducted a set of experiments using a forced divergent barotropic vorticity (FDBV) model (see appendix). This is a useful tool for investigating the vorticity response over the subtropics and midlatitudes induced by tropical divergence anomalies (Sardeshmukh and Hoskins 1988; Krishnan and Mujumdar 1999). Given the variability of the summertime upper-tropospheric winds over the $\mathrm{NH}$ subtropics (see Ambrizzi et al. 1995; Terao 1999), we have employed the FDBV model to study the circulation response at $200 \mathrm{hPa}$ during monsoon breaks.

\section{a. Circulation response to anomalous divergence}

The FDBV equation is linearized with regard to the summer monsoon basic flow which, in this case, corresponds to the JJAS climatological winds at $200 \mathrm{hPa}$ from NCEP reanalysis. In the first experiment (E1), the model is forced by the 200 -hPa divergence $\left(D^{\prime}\right)$ anomaly composite (from the NCEP reanalysis) based on monsoon break days (see Table 1). Basically, the anomalous divergence $D^{\prime}$ is related to the irrotational or the divergent component $V_{\chi}{ }^{\prime}$ of the wind field. The solution of the FDBV yields the vorticity $\zeta^{\prime}$ and streamfunction $\psi^{\prime}$ response associated with the rotational component $V_{\psi}{ }^{\prime}$ of the circulation anomaly.

The anomalous upper-level divergence used to force experiment E1 is shown in Fig. 13a. The negative anomalies over the Indian subcontinent indicate anomalous upper-tropospheric convergence (or weakened divergence) due to suppressed monsoon convection. The anomalous divergence over the Himalayan foothills and Indo-China (Fig. 13a) is consistent with the eastward shift of the Tibetan High and increased rainfall activity over the region during monsoon breaks. The overall largescale structure of the upper-level divergence anomalies 

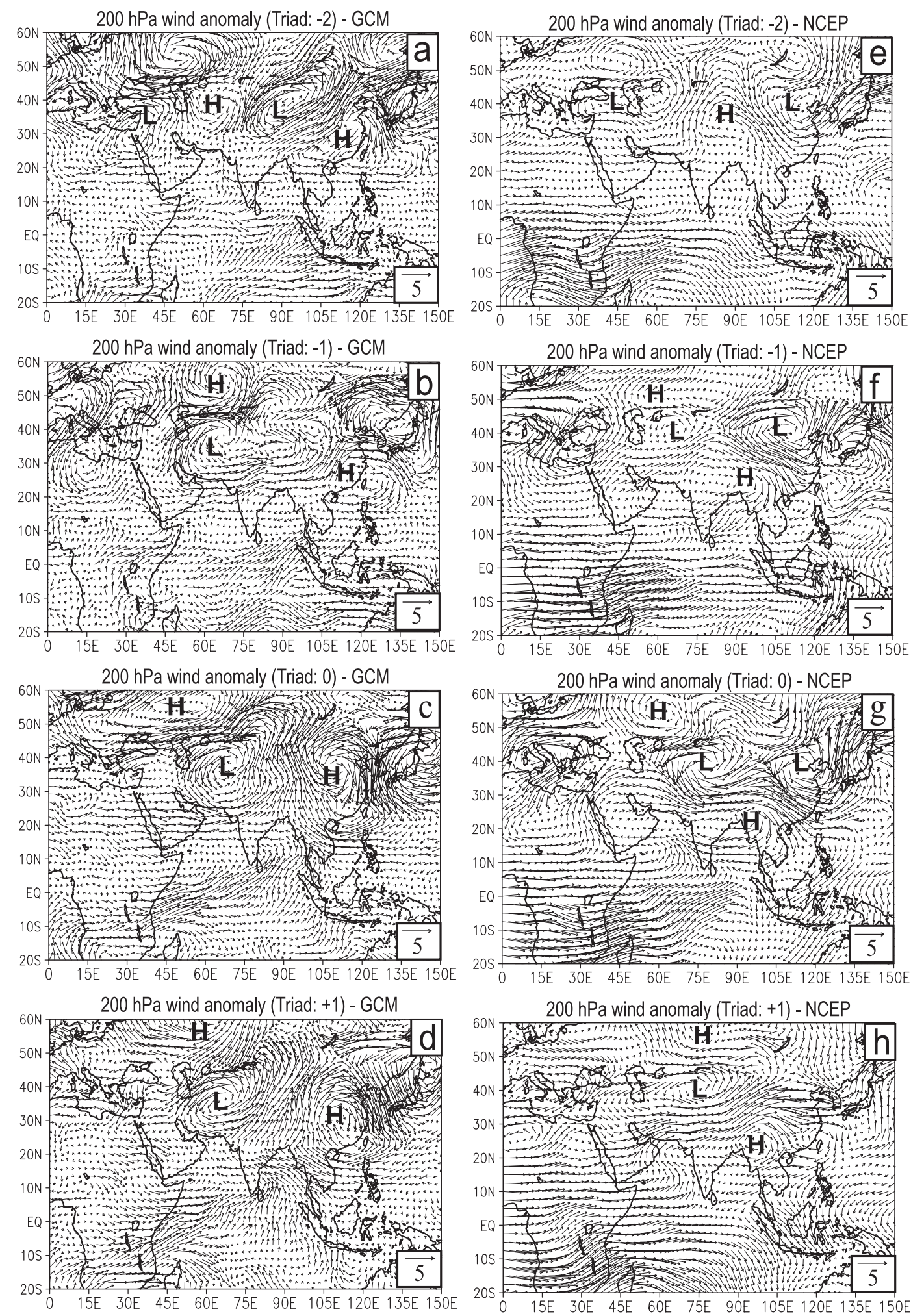

FIG. 11. Sequence of composited 200-hPa wind $\left(\mathrm{m} \mathrm{s}^{-1}\right)$ anomalies associated with the evolution of monsoon breaks in the (left) GCM and (right) NCEP reanalysis: triads (a),(e) -2, (b),(f) -1 , (c), (g) 0, and (d),(h) +1. 

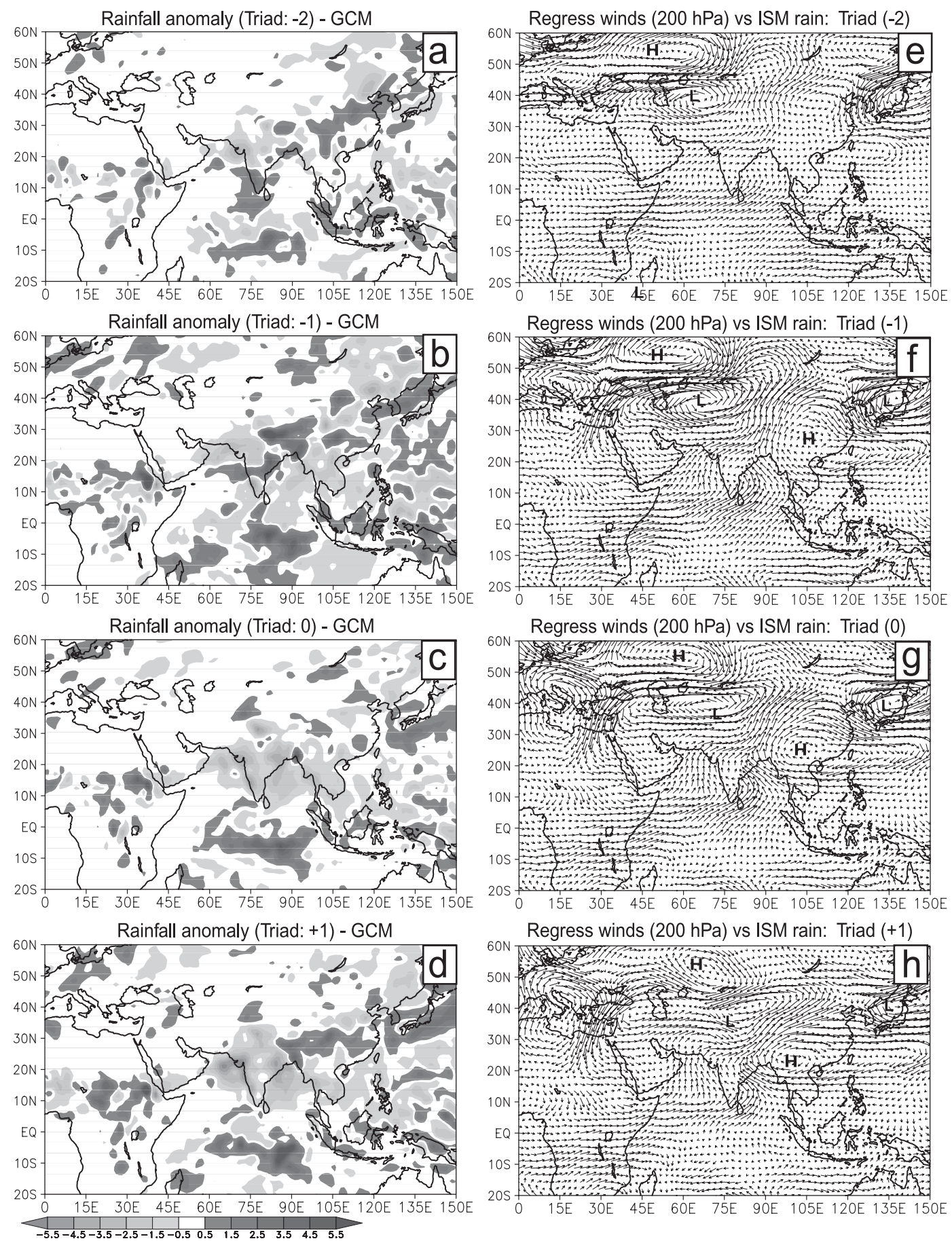

FIG. 12. (a)-(d) As in Fig. 11, but for rainfall anomalies $\left(\mathrm{mm}\right.$ day $\left.^{-1}\right)$. (e)-(h) Circulation patterns generated through lagged regression of $200-\mathrm{hPa}$ winds on the time series of daily rainfall anomalies $\left(\mathrm{mm} \mathrm{day}^{-1}\right.$ ) over the Indian region $\left(12^{\circ}-32^{\circ} \mathrm{N}, 70^{\circ}-90^{\circ} \mathrm{E}\right)$. The units are $\mathrm{m} \mathrm{s}^{-1}(\mathrm{std} \mathrm{dev})^{-1}$ of rainfall time series. The lags in each panel are expressed in triads. 

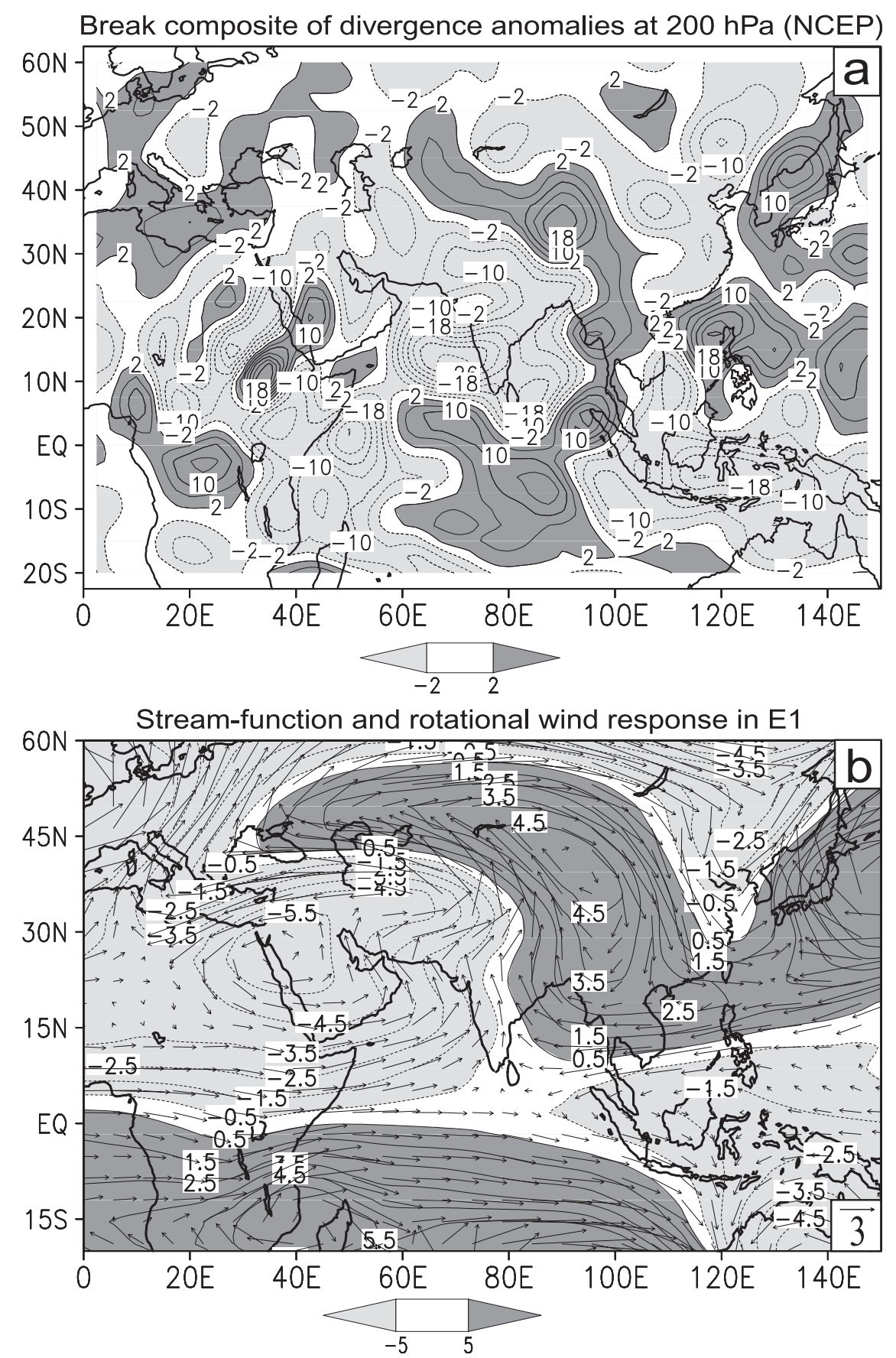

FIG. 13. (a) Composite of 200-hPa divergence $\left(\times 10^{-7} \mathrm{~s}^{-1}\right)$ anomalies based on monsoon break days (see Table 1) used to force experiment E1. (b) Streamfunction $\left(\times 10^{6} \mathrm{~m}^{2} \mathrm{~s}^{-1}\right)$ and rotational wind $\left(\mathrm{m} \mathrm{s}^{-1}\right)$ response simulated by $\mathrm{E} 1$.

over the Asian monsoon region reveals a quadrupole pattern having negative anomalies over the Indian subcontinent, Maritime Indonesia, and the equatorial west Pacific and positive anomalies over equatorial eastern Indian Ocean and the Far East region covering eastern China, the northern Philippines, Taiwan, and
Japan. This pattern of divergence anomalies is consistent with the convective anomalies seen typically during weak monsoon phases (see Lau and Chan 1986; Krishnan et al. 2000; Sperber et al. 2000; Annamalai and Sperber 2005). Outside the monsoon region, positive divergence anomalies are seen over the Mediterranean 
region (Fig. 13a). This feature can be interpreted in terms of the monsoon-desert mechanism of Rodwell and Hoskins (1996), which explains the summer dryness over the Mediterranean and Eastern Sahara as a consequence of the descent induced by the South Asian monsoonal heating. The anomalous upper-level divergence (i.e., above-normal convergence) over the Mediterranean in Fig. 13a basically indicates weaker descent and is consistent with the weak phase of the South Asian monsoon.

The streamfunction $\psi^{\prime}$ and rotational wind response $V_{\psi}{ }^{\prime}$ in E1 (Fig. 13b) shows westerly anomalies extending eastward from Africa into the Arabian Sea and India. In fact, the prevalence of westerly anomalies is seen as far as the tropical Indian Ocean and the SH subtropics. A striking feature in Fig. 13b is the wavy pattern consisting of a cyclonic anomaly (negative $\psi^{\prime}$ ) over east Africa, Arabia, Pakistan, and northern India; an anomalous ridge (positive $\psi^{\prime}$ ) located downstream over East Asia at $\sim 100^{\circ} \mathrm{E}$; a subsequent trough west of Korea; and an anticyclonic anomaly farther eastward over Japan. Notice that the East Asia ridge in Fig. 13b extends meridionally into the midlatitudes and shows westward elongation beyond $30^{\circ} \mathrm{N}$. The upper-level cyclonic anomaly to the west of the Indian subcontinent can be interpreted as an offequatorial Rossby response to anomalous upper-level convergence over the monsoon region, while the anomalous ridge over East Asia is suggestive of downstream Rossby wave dispersion (Hoskins and Karoly 1981; Sardeshmukh and Hoskins 1988).

\section{b. Circulation response to suppressed monsoon convection}

In the E1 experiment, the anomalous divergence used to force the FDBV model was determined from the wind field. To substantiate and attribute the effects of suppressed monsoon convection on the rotational wind response, it is necessary to relate the divergence and convective anomalies during monsoon breaks. Keeping this in mind, we have conducted two other experiments, E2 and E3, which allow us to infer the role of suppressed monsoon convection in affecting the large-scale circulation response during monsoon breaks.

In the E2 and E3 experiments, the forcing due to the monsoon break divergent anomalies is estimated indirectly from the convection changes provided by the observed OLR, which is a good proxy for tropical convection. Deep tropical convection is characterized by low cloud-top temperatures and small OLR values, whereas large OLR indicates scarcity or absence of cloud cover. Julian (1984) proposed an objective scheme for determining tropical divergence by transforming satellite-based OLR data so that the conventional observational database is supplemented with indirect and independent information on the tropical wind field, which is particularly relevant for those regions in which large-scale organized convection occurs. In this method, the OLR data is first expressed in equivalent blackbody temperature (EBB), which is later scaled to divergence at different pressure levels. More details are given in Julian (1984).

We have applied the scheme of Julian (1984) for estimating the divergence at $200 \mathrm{hPa}$ using global OLR data in the $20^{\circ} \mathrm{S}-35^{\circ} \mathrm{N}$ latitude belt for the monsoon break days given in Table 1 . Because convection variations over the Indian subcontinent and the Asian monsoon region extend north of $30^{\circ} \mathrm{N}$, we use the OLR data up to $35^{\circ} \mathrm{N}$ for estimating the divergence. Figure $14 \mathrm{a}$ shows the break-monsoon composite of OLR anomaly and Fig. 14b shows the estimated divergence anomalies at $200 \mathrm{hPa}$. In constructing the OLR (divergence) anomalies, we have subtracted the daily climatological mean for that particular day when a break occurred. The large positive OLR anomaly over north central India, with a maximum value of $\sim 45 \mathrm{~W} \mathrm{~m}^{-2}$, represents strong suppression of monsoon convection. The corresponding upper-level divergence anomalies (Fig. 14b) show anomalous convergence as large as $-4 \times 10^{-6} \mathrm{~s}^{-1}$ over the subcontinent. Notice that the large-scale breakmonsoon quadrupole structure of the convection/ divergence anomaly is distinctly captured in Figs. 14a,b.

The forcing in the E2 experiment is the $200-\mathrm{hPa}$ divergence anomalies estimated from OLR in the $20^{\circ} \mathrm{S}-$ $35^{\circ} \mathrm{N}$ latitude belt for the whole globe; it is shown over the subdomain $20^{\circ} \mathrm{S}-35^{\circ} \mathrm{N}, 40^{\circ}-140^{\circ} \mathrm{E}$ in Fig. $14 \mathrm{~b}$. In the E3 experiment, the anomalous divergence (Fig. 14e) is estimated only for the suppressed monsoon convection (i.e., positive OLR anomalies) over the Indian region and neighborhood $\left(0^{\circ}-35^{\circ} \mathrm{N}, 55^{\circ}-95^{\circ} \mathrm{E}\right)$; elsewhere the divergence anomalies are set to zero (Fig. 14d). Because the anomalous forcing in E3 (Fig. 14d) is estimated exclusively over the Indian region and vicinity, the model response in this case allows interpretation of the effects of suppressed monsoon convection on the circulation response during monsoon breaks.

The streamfunction and rotational wind response from the E2 and E3 experiments are shown in Figs. 14c and $14 \mathrm{f}$, respectively. Both experiments show a largescale cyclonic anomaly to the west of $90^{\circ} \mathrm{E}$, with anomalous westerlies extending eastward from the Mediterranean region into northern Africa, the Middle East, the Arabian Sea, and northwest India. Farther to the east, a well-defined anticyclonic anomaly can be seen around $100^{\circ} \mathrm{E}$ over East Asia in E2 and E3. The center of the anticyclonic anomaly is located around $40^{\circ} \mathrm{N}$, and a north-south ridge can be seen extending from the 

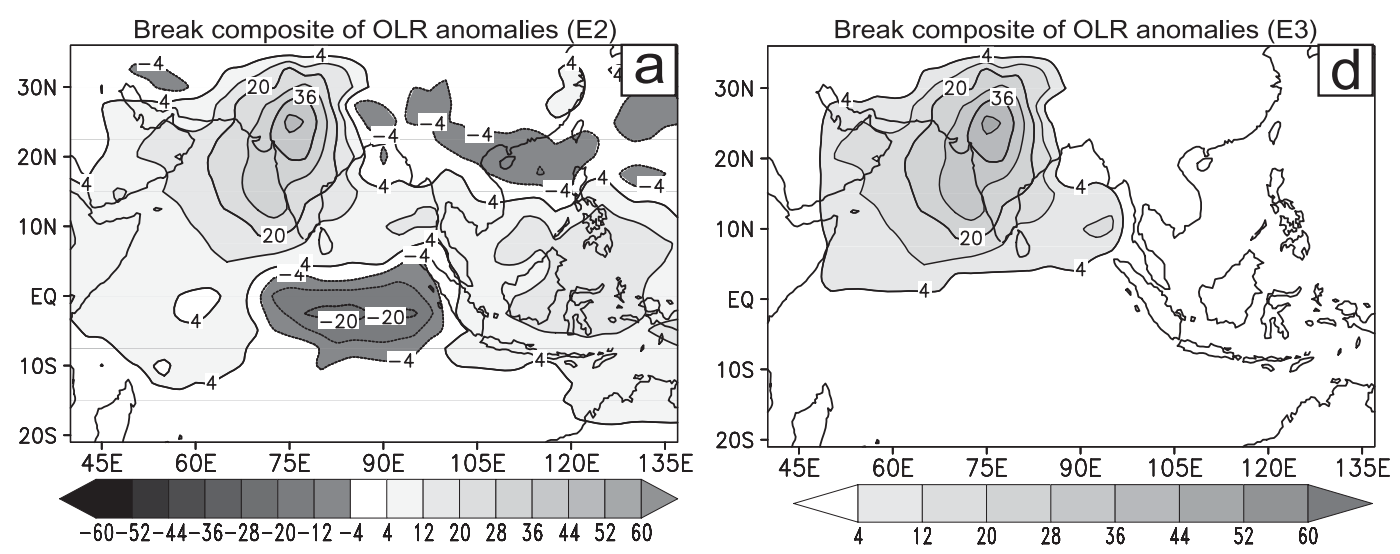

Estimated divergence anomalies at $200 \mathrm{hPa}(\mathrm{E} 2)$


FIG. 14. (a) Composite of OLR $\left(\mathrm{W} \mathrm{m}^{-2}\right.$ ) anomalies based on monsoon break days (see Table 1). (b) Divergence anomalies $\left(\times 10^{-7} \mathrm{~s}^{-1}\right)$ at $200 \mathrm{hPa}$ estimated from OLR used to force experiment E2. (c) Streamfunction $\left(\times 10^{+6}\right.$ $\mathrm{m}^{2} \mathrm{~s}^{-1}$ ) and rotational wind $\left(\mathrm{m} \mathrm{s}^{-1}\right)$ response simulated by E2. (d) As in (a), but OLR anomalies are confined to the Indian subcontinent and its vicinity. (e),(f) As in (b),(c), respectively, but for E3.

tropics into the deep midlatitudes in Figs. 14e,f. Also, note the amplitudes of the cyclonic response to the west: the anticyclonic response over East Asia is stronger in E2 than in E3.

The anticyclonic anomalies over East Asia in E2 and E3 are of particular interest to our discussion. It is important to note that the forcing in E3 experiment is es- sentially from the upper-level convergence anomalies, associated with suppressed monsoon convection over the Indian region. In this case, the East Asian anticyclonic anomaly can be interpreted as Rossby wave dispersion downstream of the anomalous forcing (e.g., Hoskins and Karoly 1981; Sardeshmukh and Hoskins 1988). However, in the case of E2 the forcing has an additional 
contribution from the upper-level divergence anomalies associated with the enhanced convective activity to the east of $90^{\circ} \mathrm{E}$ (Fig. 14b). Consequently, the East Asian anticyclonic anomaly is stronger in E2 as compared to E3. In particular, a significant strengthening of the tropical easterly anomalies is clearly evident in E2 around $15^{\circ} \mathrm{N}$ to the east of $100^{\circ} \mathrm{E}$ (Fig. $14 \mathrm{c}$ ) and is associated with the eastward shift of the Tibetan anticyclone.

Based on the above results, it is suggested that the stagnant ridge over East Asia during monsoon breaks (Raman and Rao 1981) largely represents a combined outcome from two dynamical effects: (i) downstream dispersion of Rossby waves and (ii) the eastward shift of the Tibetan anticyclone. In the former, the anticyclonic response over East Asia manifests mostly over the extratropics and the Rossby wave dispersion involves anomalous vorticity generation through interactions between the subtropical westerlies and the upper-level convergence anomalies from suppressed monsoon convection over the Indian region. In the latter, the response is predominantly over the tropics and is linked to the increased rainfall activity over the Himalayan foothills and Indo-China, with an accompanying eastward shift of the Tibetan anticyclone (see Ramaswamy 1962; Krishnamurti et al. 1989).

\section{c. Monsoon and midlatitude interactions}

The present findings, when juxtaposed, provide a consistent explanation for an interactive feedback between the monsoon and the midlatitude circulation anomalies, which can cause prolonged monsoon breaks, thereby leading to the occurrence of droughts over the subcontinent. In this feedback, an anomalous decrease of upper-level divergence from suppressed monsoon convection over the Indian region induces a Rossby wave response, and the associated vorticity changes manifest in the form of an upper-level cyclonic anomaly/trough to the west of the subcontinent (see Rodwell and Hoskins 1996). The FDBV model experiments suggest that the anomalous Rossby waves tend to disperse in the presence of the subtropical westerlies and give rise to an anticyclonic anomaly farther downstream over East Asia. The downstream Rossby response together with the eastward shift of the Tibetan anticyclone generates a deep north-south ridge over East Asia, which anchors the cyclonic anomalies over WCA and the Indo-Pak region.

Furthermore, the AGCM simulations and reanalysis data show that the anomalous midlatitude troughs over WCA produce cooling in the upper and middle troposphere through cold-air advection and decrease the north-south temperature gradient over the monsoon region. Also, the southward intrusion of cold and dry midlatitude winds over northwest India can inhibit convective instability, so that the suppressed convection can further weaken the monsoon flow. Thus, on the one hand, the midlatitude circulation anomalies can exert influence on the summer monsoon circulation; on the other hand, the anomalous decrease of monsoon convection (upper-level divergence) tends to reinforce the anomalous midlatitude circulation pattern through Rossby-wave dispersion. This interactive feedback provides persistence and allows the midlatitude circulation anomalies to amplify and in turn enables sustenance of the break-monsoon condition over the Indian landmass.

To what extent such a feedback continues also depends on processes that tend to counteract and terminate the break-monsoon condition. For example, any synoptic situation that weakens the East Asia ridge or allows the ridge to move eastward should be conducive for termination of the positive feedback. A full-fledged understanding of the various feedback effects requires further studies. The simulated droughts were typically associated with four to six break spells within the summer monsoon season; some of the longest breaks had typical durations of $\sim 11-15$ days. In noting these points, it is realized that external influences like the MJO, ENSO, Indian Ocean SST anomalies, and so on could affect the large-scale circulation so as to sustain or weaken the monsoon breaks. Here it must be reiterated that our intention is not to preclude the effects of such external forcing mechanisms, which may either reinforce or diminish the internally forced response. Instead, the idea is to provide a self-consistent explanation of how extended monsoon breaks can occur through internal feedbacks between the monsoon and midlatitude circulation. In fact, this knowledge would be useful for future studies on how the properties of monsoon breaks might respond to various climatic phenomena.

\section{Concluding remarks}

Although observational studies in the past have reported the occurrence of well-defined midlatitude circulation anomalies during weak monsoon phases, the underlying dynamics sustaining these circulation patterns has remained elusive. By combining highresolution AGCM simulations, data diagnostics, and experiments with a simplified vorticity (FDBV) model, we have made an attempt to elucidate the basic dynamics of the monsoon-midlatitude teleconnection and its role in causing long-lasting breaks in the monsoon rainfall, thus leading to droughtlike conditions over the subcontinent. Here, we shall recapitulate the main findings of this study. 
The AGCM simulation in this study is a 20 -yr integration of a high-resolution (T106) model with climatological SST specified as lower boundary condition and repeats every year during the course of the long run. The mean features of the boreal summer monsoon circulation and rainfall distribution over the subcontinent are robust and fairly realistic in the simulation. Despite using a climatological SST boundary condition, the 20-yr simulation exhibits remarkable interannual variations in the Indian summer monsoon rainfall. It is noted that the level of simulated interannual variability of monsoon rainfall is comparable with the level of observed rainfall variability, with the 20-yr run showing incidences of four monsoon droughts. Detailed analyses suggest that the simulated large-scale circulation anomalies during drought periods share several common features noticed in observations, thus indicating the robustness of the AGCM-simulated monsoon variability. In particular, the monsoon droughts in the AGCM are characterized by well-defined quasi-stationary circulation anomalies extending over the subtropics and midlatitudes in the middle and upper troposphere. A careful examination of the source of internally forced monsoon droughts in the simulation points to the role of extended breaks that occur on subseasonal time scales. The spatial structure of the monsoon break anomalies is found to be projected on the structure of the seasonal-scale drought anomalies, thus indicating the importance of subseasonal variability in giving rise to the monsoon internal dynamics.

A distinctive aspect of this internal dynamics is the occurrence of a monsoon-midlatitude linkage during break periods. The associated circulation pattern extends across continental Eurasia in the middle and upper troposphere and comprises of a cyclonic anomaly over WCA, a meridionally deep anticyclonic anomaly over East Asia $\left(\sim 100^{\circ} \mathrm{E}\right)$, and a cyclonic anomaly over the Far East. The present results show that this circulation pattern is related to Rossby wave dispersion forced by the suppressed monsoon convection in presence of the subtropical westerlies. In particular, it is noticed that the combined effects of downstream Rossby wave dispersion and the eastward shift of the Tibetan anticyclone during monsoon breaks gives rise to an anomalous north-south ridge over East Asia. Although this stagnant feature over East Asia enables the cyclonic anomalies to be anchored to the west of the subcontinent, the anomalous westerlies over WCA and Indo-Pak produce cooling in the middle and upper-troposphere through cold-air advection, thus leading to a decreased meridional thermal contrast over the monsoon region. Additionally, the southward intrusion of the cold and dry midlatitude winds over northwest India can inhibit convective instability, so the suppressed monsoon convection may further weaken the monsoon flow. In short, the present results point to an interactive feedback between the monsoon and midlatitude circulation that allows the Eurasian circulation anomalies to persist and amplify, in turn enabling sustenance of the break-monsoon conditions.

This study has focused mainly on dynamical aspects relating to monsoon and midlatitude interactions during monsoon droughts. Bhat (2006) reported persistent and strong inversions at $800 \mathrm{hPa}$ over the eastern Arabian Sea during the July 2002 drought using the Arabian Sea Monsoon Experiment (ARMEX) measurements, and back-trajectory analysis showed a prevalence of dry desert air over the region. Further studies are needed to unravel the origin of dryness; and partition the relative effects of extratropical intrusions and declining monsoon rainfall activity in contributing to the anomalous drying during monsoon droughts. In bringing out the monsoonmidlatitude interactions during drought periods, our intention is not to rule out the influence of external forcing on monsoon variability. While it is realized that several monsoon droughts in the past have co-occurred with $\mathrm{El}$ Niño events, it is equally important to recognize that the proposed monsoon-midlatitude linkage can be well independent of external forcing like ENSO. In fact, this point is supported by the work of Ding and Wang (2005) that identified a circumglobal teleconnection (CGT) - a standing oscillation that is primarily confined within the waveguide associated with the $\mathrm{NH}$ summer jetstream. Ding and Wang (2005) noted that the CGT has significant correlations with the Indian summer monsoon (ISM) and ENSO. However, during periods of normal ISM, they found that the CGT-ENSO correlation disappeared; on the other hand, the CGT-ISM correlation remained significant, even in the absence of El Niño or La Niña. Also, the proposed internal dynamics does not conflict in any way with the concept of externally forced monsoon variability. Instead, this knowledge could be used to supplement and enhance the understanding of how various climatic phenomena might alter the internal dynamics over the monsoon region.

Acknowledgments. We thank Prof. B. N. Goswami, Director, IITM, for the valuable discussions and the support. We are grateful to the two anonymous reviewers and to editor Prof. Bin Wang for the thought-provoking comments that helped in improving the manuscript. We acknowledge Dr. Sahai and Mrs. Sujata Mandke for making available to us rainfall output from the PUM simulation. This work was funded by the INDOMOD (ISP-1.5) project. The 20-year AGCM run was conducted using a Cray-T932 supercomputer at NIED, Tsukuba, when RK was a visiting researcher at FRSGC, Japan. 


\section{APPENDIX}

\section{The Forced Divergent Barotropic Vorticity Equation}

The FDBV equation is written as

$$
\frac{\partial \varsigma}{\partial t}+\mathbf{V} \cdot \nabla(\zeta+f)=-(\zeta+f) \nabla \cdot \mathbf{V}+F .
$$

The term $\mathbf{V} \cdot \nabla(\zeta+f)$ represents the advection of absolute vorticity by horizontal wind; $-(\zeta+f) \nabla \cdot \mathbf{V}$ is the vorticity stretching term and $F$ represents frictional damping. The model details are given in Krishnan and Mujumdar (1999). We use the spectral method for solving the FDBV on a sphere by expanding the variables using spherical harmonics. The model has R20 horizontal resolution (rhomboidal truncation at zonal wavenumber 20) and uses an explicit leapfrog time integration with a 1 -h time step. The frictional damping $F$ has an $e$-folding time scale of five days. Starting from rest, the model is integrated for 100 days with the divergent forcing kept fixed; the solution on the 100th day is taken as the equilibrium response.

\section{REFERENCES}

Ambrizzi, T., B. J. Hoskins, and H.-H. Hsu, 1995: Rossby wave propagation and teleconnection patterns in the austral winter. J. Atmos. Sci., 52, 3661-3672.

Annamalai, H., and K. R. Sperber, 2005: Regional heat sources and the active and break phases of boreal summer intraseasonal (30-50 day) variability. J. Atmos. Sci., 62, 2726-2748.

Asnani, G. C., 1993: Tropical Meteorology. Vol. 1. Indian Institute of Tropical Meteorology, $603 \mathrm{pp}$.

Bhat, G. S., 2006: The Indian drought of 2002 - A sub-seasonal phenomenon? Quart. J. Roy. Meteor. Soc., 132, 2583-2602.

Brown, R. G., and C. Zhang, 1997: Variability of midtropospheric moisture and its effect on cloud-top height distribution during TOGA COARE. J. Atmos. Sci., 54, 2760-2774.

Charney, J. G., and J. Shukla, 1981: Predictability of monsoons. Monsoon Dynamics, J. Lighthill and R. P. Pearce, Eds., Cambridge University Press, 99-109.

Ding, Q., and B. Wang, 2005: Circumglobal teleconnection in the Northern Hemisphere summer. J. Climate, 18, 3483-3505.

$\longrightarrow$, and - 2007: Intraseasonal teleconnection between the Eurasian wave train and the Indian monsoon. J. Climate, 20, 3751-3767.

Enomoto, T., B. J. Hoskins, and Y. Matsuda, 2003: The formation mechanism of the Bonin high in August. Quart. J. Roy. Meteor. Soc., 129, 157-178.

Ferranti, L., J. M. Slingo, T. N. Palmer, and B. J. Hoskins, 1997: Relations between interannual and intraseasonal monsoon variability as diagnosed from AMIP integrations. Quart. J. Roy. Meteor. Soc., 123, 1323-1357.

Flohn, H., 1957: Large-scale aspects of the "summer monsoon" in South and East Asia. J. Meteor. Soc. Japan, 75, 180-186.

Gadgil, S., and S. Sajani, 1998: Monsoon precipitation in the AMIP runs. Climate Dyn., 14, 659-689.
- and P. V. Joseph, 2003: On breaks of the Indian monsoon. $J$. Earth Syst. Sci., 112, 529-558.

Goswami, B. N., 1998: Interannual variations of Indian summer monsoon in a GCM: External conditions versus internal feedbacks. J. Climate, 11, 501-522.

—_, and R. S. Ajaya Mohan, 2001: Intraseasonal oscillations and interannual variability of the Indian summer monsoon. $J$. Climate, 14, 1180-1198.

— , and — 2005: Dynamics of "internal" interannual variability of the Indian summer monsoon in a GCM. J. Geophys. Res., 110, D24104, doi:10.1029/2005JD006042.

Hahn, D. G., and S. Manabe, 1975: The role of mountains in the south Asian monsoon circulation. J. Atmos. Sci., 32, 15151541.

Hoskins, B. J., and D. J. Karoly, 1981: The steady linear response of a spherical atmosphere to thermal and orographic forcing. J. Atmos. Sci., 38, 1179-1196.

JMA, 1993: Outline of operational numerical weather prediction at the Japan Meteorological Agency: Appendix to progress report on Numerical Weather Prediction. Japan Meteorological Agency, 128 pp.

Joseph, P. V., and J. Srinivasan, 1999: Rossby waves in May and the Indian summer monsoon rainfall. Tellus, 51A, 854-864.

Julian, P. R., 1984: Objective analysis in the tropics: A proposed scheme. Mon. Wea. Rev., 112, 1752-1767.

Kalnay, E., and Coauthors, 1996: The NCEP/NCAR 40-Year Reanalysis Project. Bull. Amer. Meteor. Soc., 77, 437-471.

Kang, I.-S., and Coauthors, 2002: Intercomparison of the climatological variations of Asian summer monsoon precipitation simulated by 10 GCMs. Climate Dyn., 19, 383-395.

Kar, S. C., M. Sugi, and N. Sato, 1996: Simulation of the Indian summer monsoon and its variability using the JMA global model. Pap. Meteor. Geophys., 47, 65-101.

,$- \longrightarrow$, and $\longrightarrow, 2001$ : Interannual variability of the Indian summer monsoon and internal variability in the JMA global model simulations. J. Meteor. Soc. Japan, 79, 607-623.

Keshavamurty, R. N., and S. T. Awade, 1974: Dynamical abnormalities associated with drought in the Asiatic summer monsoon. Indian J. Meteor. Geophys., 25, 257-266.

Koteswaram, P., 1958: The easterly jet stream in the tropics. Tellus, 10, 43-56.

Kripalani, R. H., A. Kulkarni, and S. V. Singh, 1997: Association of the Indian summer monsoon with the Northern Hemisphere midlatitude circulation. Int. J. Climatol., 17, 1055-1067.

Krishnamurti, T. N., 1973: Tibetan high and upper tropospheric tropical circulation during northern summer. Bull. Amer. Meteor. Soc., 54, 1234-1249.

H. S. Bedi, and M. Subramaniam, 1989: The summer monsoon of 1987. J. Climate, 2, 321-340.

Krishnan, R., and M. Mujumdar, 1999: Remotely and regionally forced pre-monsoon signals over northern India and neighbourhood. Quart. J. Roy. Meteor. Soc., 125, 55-78.

, and M. Sugi, 2001: Baiu rainfall variability and associated monsoon teleconnections. J. Meteor. Soc. Japan, 79, 851-860. , C. Venkatesan, and R. N. Keshavamurty, 1998: Dynamics of upper tropospheric stationary wave anomalies induced by ENSO during the northern summer: A GCM study. Proc. Indian Acad. Sci. (Earth Planet. Sci.), 107, 65-90.

— C. Zhang, and M. Sugi, 2000: Dynamics of breaks in the Indian summer monsoon. J. Atmos. Sci., 57, 1354-1372. , M. Mujumdar, V. Vaidya, K. V. Ramesh, and V. Satyan, 2003: The abnormal Indian summer monsoon of 2000. J. Climate, 16, 1177-1194. 
— K. V. Ramesh, B. K. Samala, G. Meyers, J. Slingo, and M. J. Fennessy, 2006: Indian Ocean-monsoon coupled interactions and impending monsoon droughts. Geophys. Res. Lett., 33, L08711, doi:10.1029/2006GL025811.

Lau, K.-M., and P. Chan, 1986: Aspects of the 40-50-day oscillation during the northern summer as inferred from outgoing longwave radiation. Mon. Wea. Rev., 114, 1354-1367.

— during the northern summer. J. Climate, 5, 140-158.

Li, C., and M. Yanai, 1996: The onset and interannual variability of the Asian summer monsoon in relation to land-sea thermal contrast. J. Climate, 9, 358-375.

Liu, Y., B. J. Hoskins, and M. Blackburn, 2007: Impact of Tibetan orography and heating on the summer flow over Asia. $J$. Meteor. Soc. Japan, 85B, 1-19.

Luo, H., and M. Yanai, 1984: The large-scale circulation and heat sources over the Tibetan Plateau and surrounding area during the early summer of 1979. Part II: Heat and moisture budgets. Mon. Wea. Rev., 112, 966-989.

Palmer, T. N., and D. L. T. Anderson, 1994: The prospects for seasonal forecasting-A review paper. Quart. J. Roy. Meteor. Soc., 120, 755-793.

Parthasarthy, B., A. A. Munot, and D. R. Kothawale, 1995: Monthly and seasonal rainfall series for All-India homogenous regions and meteorological subdivisions 1871-1994. IITM Research Rep. RR-065, Indian Institute of Tropical Meteorology, $113 \mathrm{pp}$.

Ramamurthy, K., 1969: Some aspects of "break" in the Indian southwest monsoon during July and August. India Meteorological Department Forecasting Manual, Part 4, section 18.3.

Raman, C. R. V., and Y. P. Rao, 1981: Blocking highs over Asia and monsoon droughts over India. Nature, 289, 271-273.

Ramaswamy, C., 1962: Breaks in the Indian summer monsoon as a phenomenon of interaction between the easterly and the subtropical westerly jet streams. Tellus, 14A, 337-349. and R. S. Pareek, 1978: The southwest monsoon over India and its teleconnections with the middle and upper tropospheric flow patterns over the Southern Hemisphere. Tellus, 30, 126-135.

Rodwell, M. J., 1997: Breaks in the Asian monsoon: The influence of the Southern Hemisphere weather systems. J. Atmos. Sci., 54, 2597-2611.

—, and B. J. Hoskins, 1996: Monsoons and the dynamics of deserts. Quart. J. Roy. Meteor. Soc., 122, 1385-1404.

Sardeshmukh, P. D., and B. J. Hoskins, 1988: The generation of global rotational flow by steady idealized tropical divergence. J. Atmos. Sci., 45, 1228-1251.

Sperber, K. R., and T. N. Palmer, 1996: Interannual tropical rainfall variability in general circulation model simulations associated with the atmospheric model intercomparison project. J. Climate, 9, 2727-2750.

- J. M. Slingo, and H. Annamalai, 2000: Predictability and the relationship between subseasonal and interannual variability during the Asian summer monsoon. Quart. J. Roy. Meteor. Soc., 126, 2545-2574.

Sugi, M., K. Kuma, K. Tada, K. Tamiya, N. Hasegawa, T. Iwasaki, S. Yamada, and T. Kitade, 1990: Description and performance of the JMA operational global spectral model (JMAGSM88). Geophys. Mag., 43, 105-130.

, R. Kawamura, and N. Sato, 1997: A study of SST-forced variability and potential predictability of seasonal mean fields using the JMA global model. J. Meteor. Soc. Japan, $\mathbf{7 5}$, 717-736.

Terao, T., 1999: The zonal wavelength of the quasi-stationary Rossby waves trapped in the westerly jet. J. Meteor. Soc. Japan, 77, 687-699.

Wang, B., I.-S. Kang, and J.-Y. Lee, 2004: Ensemble simulation of Asian-Australian monsoon variability by 11 AGCMs. $J$. Climate, 17, 803-818.

Yanai, M., and G.-X. Wu, 2006: Effects of the Tibetan Plateau. The Asian-Monsoon, B. Wang, Ed., Springer-Praxis, 513-549. 